\title{
UN ACERCAMIENTO A LA SITUACIÓN HIGIÉNICO-SANITARIA DE LOS DISTRITOS DE MADRID EN EL TRÁNSITO DEL SIGLO XIX AL XX*
}

\author{
$M^{a}$ Isabel Porras Gallo \\ Unidad de Historia de la Medicina, Facultad de Medicina de Albacete, \\ Centro Regional de Investigaciones Biomédicas (CRIB), Universidad de Castilla-La Mancha
}

\begin{abstract}
RESUMEN
Los testimonios médicos científico-profesionales de la época ofrecen una opinión generalizada sobre la mala situación higiénico-sanitaria de Madrid y de buena parte de sus distritos en el tránsito del siglo XIX al XX, tanto como para ser calificada como «ciudad de la muerte». Pues bien, en el presente trabajo, utilizando como principales fuentes las Estadísticas Demográfico-Sanitarias del Ayuntamiento y del Ministerio de la Gobernación, se pretende contrastar la información contenida en dichos testimonios y en los estudios historiográficos realizados hasta ahora con la proporcionada por el examen de las variaciones registradas en la mortalidad de los distritos de Madrid entre 1880 y 1931. A tal objeto, el estudio se ha centrado en el análisis de las modificaciones habidas en la mortalidad general e infantil, y en las tasas específicas de algunas enfermedades (diarrea y enteritis en menores de dos años, viruela, difteria, tuberculosis pulmonar, gripe y resto enfermedades respiratorias) de los distintos distritos madrileños. Con ello se pretende hacer un acercamiento a su estado higiénico-sanitario en el período indicado.
\end{abstract}

PALABRAS CLAVE: higiene urbana, Madrid, siglos XIX-XX, mortalidad urbana, transición sanitaria.

\section{SUMMARY}

The medical statements of the time show us a common opinion of the deplorable sanitary conditions of Madrid and of the most of its districts in the turn of the XIX century. This situation was so terrible that Madrid was named the «death city». In this project, using as the main sources the Healthy Demographic Statitiscs of the Town Council and of the Home Office, we aim to compare the information appeared in these statements and in the historiography studies with the one obtained by the exam of the variations in the mortality of Madrid districts between 1880 and 1931. In order to do that, this project is focused on the analyse of the changes on the general and infant mortalities and on the different Madrid districts rates of some diseases such as diarrhea and enteritis in under-2s, smallpox, diphtheria, pulmonary tuberculosis, flu and the other respiratory diseases. With all of this we try to know better its sanitary conditions in the period mentioned before.

KEY WORDS: urban hygiene, Madrid, $19^{\text {th }}-20^{\text {th }}$ centuries, city mortality, sanitary transition.

* Este trabajo forma parte del Proyecto de investigación 06/0022/1997 del Plan regional de la CAM. 


\section{INTRODUCCIÓN}

La mala situación higiénico-sanitaria de Madrid y, como expresión de ello, su elevada mortalidad, que hicieron que fueran aplicados calificativos tales como el de «ciudad de la muerte» ${ }^{1}$, se constituyeron en objeto de especial atención en el tránsito del siglo XIX al XX. Un exponente de este interés fueron los debates que desde mediados de los años setenta se desarrollaron en la prensa científico-profesional ${ }^{2}$, en las Academias $^{3}$ y en la Sociedad Española de Higiene ${ }^{4}$. En estos foros ${ }^{5}$, bajo el influjo de la importancia que la Higiene estaba cobrando y, con ello, del creciente deseo de los higienistas españoles de aumentar su peso en las tareas de saneamiento urbano ${ }^{6}$, se analizaron los posibles factores responsables de la -no por todos admitida- extraordinaria mortalidad de la capital del reino ${ }^{7}$. Se valoró el papel que podían tener tanto las condiciones topográficas, climatológicas y urbanas de la villa, como las deficiencias

1 RevengA, R. (1901), La muerte en Madrid, Madrid, E. Teodoro, p. 9. De este calificativo se hizo también eco Oldamont (1901), La Higiene pública en España, Madrid, Ed. A. de San Martín, p. 33.

2 Entre los artículos dedicados a este tema, cabe citar los siguientes: R.V. (1875), «La salud en Madrid», El Siglo Médico, 22, pp. 131-133; R.V. (1875), «La higiene en Madrid», El Siglo Médico, 22, pp. 338-341; MÉndez Álvaro, F. (1876), «La salud en Madrid», El Siglo Médico, 23, pp. 3-7; SOMOZA (1876), «Más sobre la mortalidad en Madrid», El Siglo Médico, 23, pp. 706-710; Este debate alcanzó también las páginas de The Lancet en 1888. Cfr. C.M.C. (1888), «La insalubridad de Madrid», El Siglo Médico, 35, 642-644, p. 642.

3 Sobre el contenido de las discusiones registradas en dichas instituciones, véanse: GALDO, M. M. J. de (1879), Breves reflexiones sobre algunos puntos de la Higiene Pública de Madrid. Discurso leído en la Academia Médico-quirúrgica española... en la sesión inaugural del Año Académico de 1878 a 1879 , Madrid, E. Teodoro; NiETo SERrano, M. (1882), Real Academia de Medicina (Sesiones del 19 y 26 de febrero, del 11 de marzo y del 1 de abril de 1882), El Siglo Médico, 29, pp. 173-174, 189-190, 208-209 y 272-273; y el Discurso leído en la inauguración de las sesiones de la Real Academia de Medicina en el año 1882-83, por el Doctor Matías Nieto Serrano, Secretario perpetuo, El Siglo Médico, 30, 1883, pp. 92-94.

4 Una de las iniciativas de esta sociedad fue la impresión y distribución a los socios de un programa conteniendo los principales puntos relativos a la mortalidad de Madrid y sus causas, que serían debatidos en su seno, «Sociedad Española de Higiene», El Siglo Médico, 29, 1882, pp. 695-699. Complemento de lo anterior fue la aportación del arquitecto BELMÁs, M. (1882), Discusión acerca de la mortalidad de Madrid. Discurso en la Sociedad Española de Higiene, Madrid, Sucs. Rivadeneyra. El contenido de las discusiones registradas en la citada sociedad fue resumido por MÉnDEZ Álvaro, F. (1882), La Mortalidad de Madrid, Madrid, E. Teodoro.

5 El debate continuó también en algunas monografías, como la de JiMENO AgIÚs, J. (1886), Madrid. Su población, natalidad y mortalidad, Madrid.

6 Expresas manifestaciones en este sentido, figuran en: GALDO, M. M. J. de (1879), pp. 7, 21 y 23; y PULIDO, Á (1889), «Higiene urbana con aplicación a Madrid. Discurso pronunciado en la inauguración del curso de 1888-89 de la Sociedad Española de Higiene», El Siglo Médico, 36, pp. 23-26, 51-54, 65-68 y 82-84.

7 Cortezo, Novella, Benavente y el arquitecto Belmás, alegando la inexactitud de los escasos datos estadísticos con que se contaba, cuestionaron esta afirmación. MÉNDEZ ÁlVARO, F. (1882), pp. 7-8. Con posterioridad, se manifestó en este mismo sentido Manuel Iglesias Díaz, entonces secretario de la Academia de Medicina, «Real Academia de Medicina», El Siglo Médico, 42, pp. 380-381. 
PLANO 1. DIVISIÓN ADMINISTRATIVA DE MADRID DE 1863

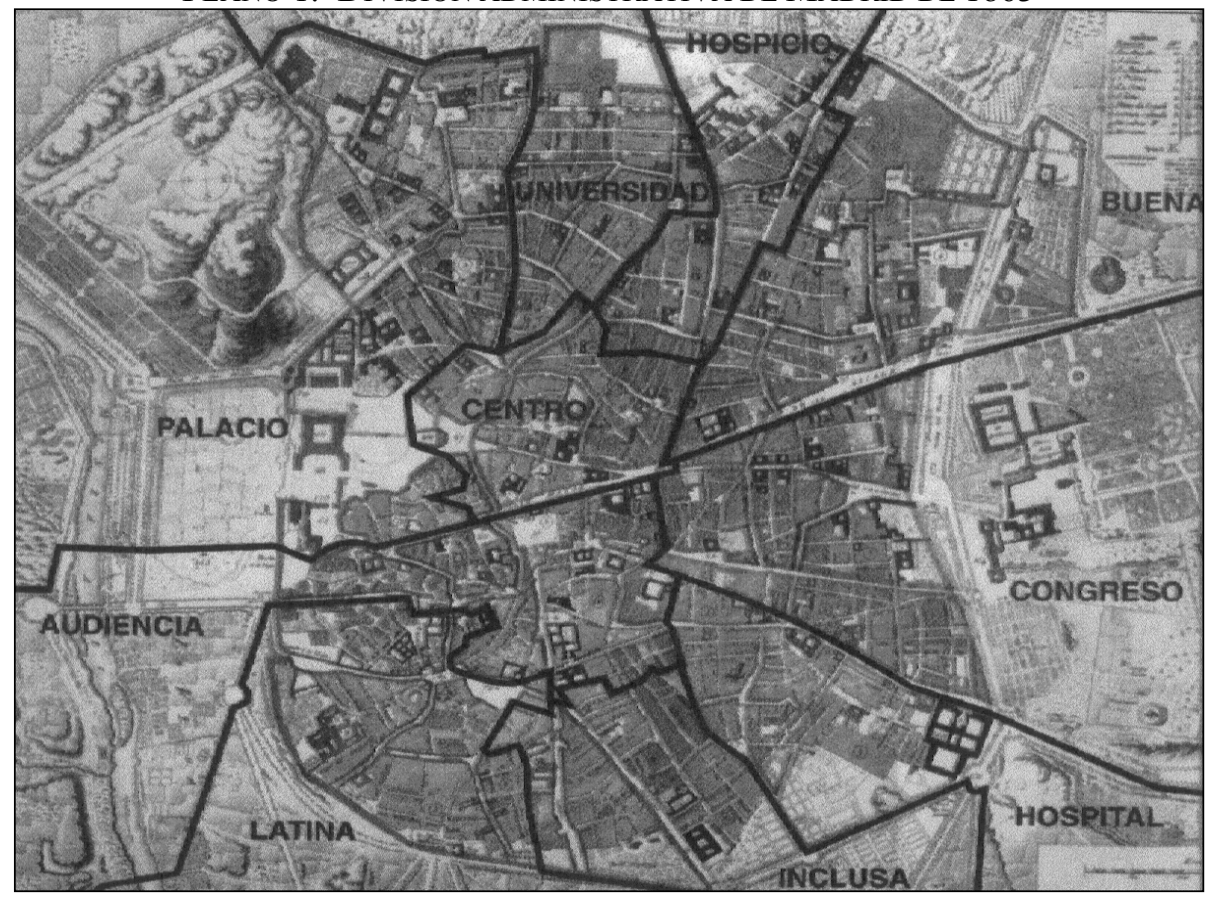

Plano 2. División ADMINISTRATIVA DE MADRID DE 1903

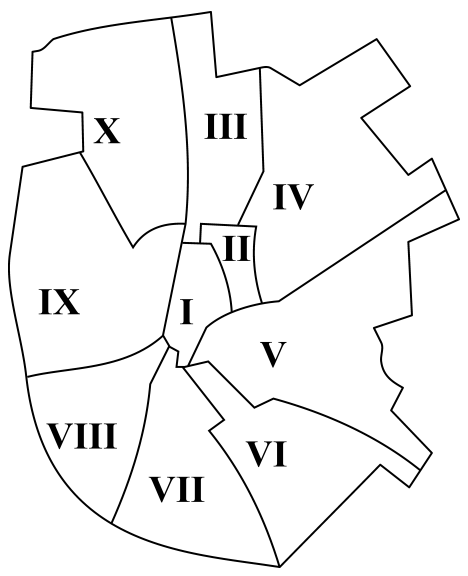

\begin{tabular}{|ll|}
\hline I & CENTRO \\
II & HOSPICIO \\
III & CHAMBERÍ \\
IV & BUENAVISTA \\
V & CONGRESO \\
VI & HOSPITAL \\
VII & INCLUSA \\
VIII & LATINA \\
IX & PALACIO \\
X & UNIVERSIDAD \\
\hline
\end{tabular}


TABLA 1. CRECIMIENTO VEGeTATIVO DE LOS DistRITOS DE MADRID

\begin{tabular}{|c|c|c|c|c|c|c|c|c|c|c|c|}
\hline 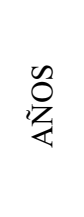 & $\begin{array}{l}\text { 党 } \\
\text { 主 }\end{array}$ & 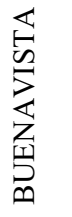 & 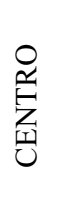 & $\begin{array}{l}0 \\
\text { W } \\
\text { પ̂ } \\
0 \\
0 \\
0 \\
0\end{array}$ & 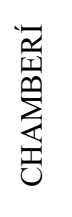 & 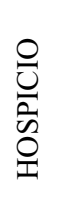 & 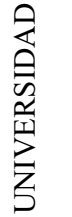 & 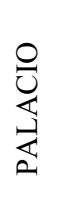 & $\begin{array}{l}\overleftrightarrow{Z} \\
\text { 岕 } \\
\text { 岁 }\end{array}$ & 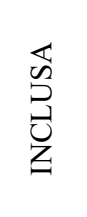 & 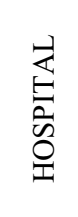 \\
\hline 1903 & 316 & 318 & 89 & 199 & 255 & 107 & -118 & 61 & 263 & 764 & -1622 \\
\hline 1904 & 644 & 283 & -157 & -26 & 56 & -56 & -208 & -59 & 170 & -458 & -170 \\
\hline 1905 & 149 & 181 & -122 & -85 & -35 & -41 & -195 & 8 & -22 & -580 & -282 \\
\hline 1906 & 225 & 247 & -4 & -89 & 212 & -93 & -65 & -38 & 44 & -866 & -528 \\
\hline 1907 & 800 & 278 & -172 & -201 & 60 & -56 & -121 & -2 & 198 & -341 & -137 \\
\hline 1908 & 3124 & 445 & 82 & 65 & 345 & 78 & 174 & 171 & 481 & -213 & 150 \\
\hline 1909 & -1869 & 81 & -114 & -390 & -219 & -183 & -316 & -115 & -409 & -1113 & -520 \\
\hline 1910 & 1834 & 372 & -8 & -226 & 346 & 73 & 130 & 60 & 161 & -376 & -114 \\
\hline 1911 & 2286 & 313 & -62 & -1 & 246 & 32 & 153 & 49 & 474 & -333 & -9 \\
\hline 1912 & 1997 & 340 & -105 & -105 & 290 & 24 & -4 & 55 & 286 & -299 & 51 \\
\hline 1913 & 1256 & 252 & -129 & -205 & 184 & -35 & 60 & 51 & 241 & -517 & -55 \\
\hline 1914 & 501 & 169 & -218 & -299 & 88 & -138 & -102 & -65 & 195 & -343 & -132 \\
\hline 1915 & 1697 & 292 & -64 & -193 & 422 & 1 & 74 & -17 & 331 & -471 & -134 \\
\hline 1916 & 1623 & 311 & -89 & -167 & 221 & -63 & 267 & 23 & 231 & -391 & -185 \\
\hline 1917 & 1621 & 254 & -133 & -252 & 160 & -39 & 119 & -47 & 449 & -339 & -83 \\
\hline 1918 & -2016 & -69 & -346 & -472 & -230 & -297 & -458 & -249 & -43 & -885 & -470 \\
\hline 1919 & -1822 & -152 & -410 & -489 & -165 & -330 & -229 & -404 & -70 & -519 & -464 \\
\hline 1920 & -127 & 62 & -281 & -273 & 12 & -138 & 32 & -244 & 165 & -546 & -384 \\
\hline 1921 & 3106 & 379 & -118 & 3 & 562 & 46 & 385 & 120 & 428 & -258 & 118 \\
\hline 1922 & 3329 & 386 & -109 & 63 & 473 & -16 & 541 & 48 & 480 & -64 & 147 \\
\hline 1923 & 3720 & 509 & -59 & -108 & 512 & -37 & 571 & 93 & 577 & 127 & 56 \\
\hline 1924 & 4637 & 519 & -79 & -109 & 619 & 120 & 599 & 102 & 718 & 479 & 145 \\
\hline 1925 & 3824 & 641 & -26 & -372 & 454 & -19 & 580 & 16 & 687 & 358 & 46 \\
\hline 1926 & 3835 & 543 & -126 & -6 & 447 & -85 & 505 & 14 & 653 & 525 & -155 \\
\hline 1927 & 4701 & 635 & -148 & 262 & 582 & -58 & 672 & 68 & 732 & 556 & -21 \\
\hline 1928 & 5577 & 836 & -121 & 535 & 693 & 41 & 790 & 49 & 659 & 472 & 128 \\
\hline 1929 & 5690 & 712 & -103 & 684 & 769 & -103 & 714 & 166 & 638 & 603 & -64 \\
\hline 1930 & 7537 & 813 & -69 & 1191 & 1008 & 45 & 903 & 95 & 802 & 935 & 145 \\
\hline 1931 & 4937 & 791 & -91 & 273 & 1076 & 9 & 900 & 144 & 864 & 1047 & -76 \\
\hline
\end{tabular}


que presentaban las viviendas, los hospitales y el sistema de evacuación de aguas fecales. Y se consideró igualmente el efecto provocado por la mala calidad y adulteraciones de los alimentos y bebidas. En consonancia con esta valoración, se reclamó la actuación de las autoridades municipales para corregir buena parte de los defectos citados y mejorar la situación higiénico-sanitaria de Madrid ${ }^{8}$. Esta discusión se generalizó y se trasladó al Real Consejo de Sanidad en 18849 ${ }^{9}$ Allí, Méndez Álvaro, en su calidad de presidente del citado organismo, elaboró un informe proponiendo un conjunto de medidas que las autoridades deberían adoptar para reducir la elevada mortalidad de los distintos puntos de España ${ }^{10}$. Entre las medidas propugnadas por el mencionado autor figuraba, además de las de Higiene pública, la necesidad de acometer estudios de epidemiología, demografía, estadística, climatología y geografía médi$\mathrm{ca}^{11}$. Precisamente, Hauser realizó un trabajo de estas características sobre Madrid en $1902^{12}$. Este estudio, modélico en su género, nos muestra una ciudad que, al inicio del siglo XX, presentaba aún graves deficiencias higiénico-urbanísticas y sanitarias, así como unas elevadas tasas de mortalidad general y de la práctica totalidad de las enfermedades infecciosas ${ }^{13}$. Además, esta situación, como remarcaba el propio autor,

8 MÉndez Álvaro, F, (1882), pp. 27-28. Una exposición más detallada de las medidas a adoptar, figura en GALDO, M. M. J. de (1879), pp. 23-28. Algunas de ellas fueron adoptadas por Moret. C.M.C. (1888), pp. 642-644. Con posterioridad, el alcalde de Madrid, José Abascal, dictó una serie de prescripciones al objeto de poder materializar dichas medidas, «Ayuntamiento Constitucional de Madrid», El Siglo Médico, 36, 1889, pp. 94-95.

9 En los años que siguieron a esta fecha se mantuvo el interés por la mala situación higiénicosanitaria de Madrid y su elevada mortalidad, abundándose en los trabajos aparecidos en la última década del siglo XIX en las causas anteriormente señaladas y recomendándose básicamente el mismo conjunto de medidas de Higiene pública que se venían proponiendo. Una muestra en este sentido lo constituyeron las publicaciones siguientes: FRANCOS RODRÍGUEZ, J. (1890), «Estado sanitario de Madrid durante los últimos meses de diciembre y enero», El Siglo Médico, 37, pp. 118-119 y 134-135; PERUJO, A. M. (1890), «La alimentación en Madrid», El Siglo Médico, 37, pp. 261-263 y 280-283; Memoria de la Junta Municipal de Sanidad de Madrid, Madrid, Impr. municipal, 1894; HERNÁNDEZ BRIZ (1894), «El paludismo en Madrid. Causas de su incremento en los últimos años», El Siglo Médico, 41, pp. 259-260; «Sesiones de la Real Academia de Medicina. Discusión sobre el paludismo en Madrid», El Siglo Médico, 42, pp. 111, 141-143, 236-238, 299-301, 316-318, 348-349, 363-365 y 380-382; RODRIGO LAVÍN, L. (1899), «La fiebre tifoidea en Madrid. Las aguas del bajo Abroñigal», El Siglo Médico, 46, pp. 610-613; ÚBEDA y CORREAL, J. (1900), Medios de disminuir la mortalidad en Madrid, Madrid, Impr. Cuerpo de Administración militar.

10 MÉndez Álvaro, F. (1884), «Informe del Real Consejo de Sanidad proponiendo las medidas más convenientes para minorar la mortalidad en España», El Siglo Médico, 31, pp. 465-469, 482-486 y 498-502.

11 Ibidem, pp. 500-501.

12 HAUSER, Ph. (1902), Madrid bajo el punto de vista médico-social, Madrid, Sucs. Rivadeneyra, 2 vols. [En adelante, citaré por la reedición de esta obra preparada por Carmen del Moral y publicada por la Editora Nacional (Madrid) en 1979]. Con anterioridad, este mismo autor había realizado un estudio similar sobre la ciudad de Sevilla: HAUSER, Ph. (1882-1884), Estudios médico-topográficos y médicosociales de Sevilla, Sevilla-Madrid, 2 vols.

13 Sobre las tasas de mortalidad general y las distintas enfermedades infecciosas, véase: HAUSER, Ph. (1979), vol. 1, p. 542 y vol. 2, pp. 41-155. 
se hallaba desigualmente repartida entre sus distintos distritos. De hecho, las peores condiciones higiénicas y la mayor mortalidad correspondían a Inclusa, Hospital, Latina y Universidad, mientras que Centro, Congreso y Buenavista presentaban las mejores condiciones y las menores tasas. A su vez, Audiencia, Palacio y Hospicio ocupaban una posición intermedia ${ }^{14}$. Era en los distritos menos favorecidos en los que se concentraba la mayor parte de las viviendas y barrios insalubres, careciendo la mayoría de sus calles de alcantarillado y faltando el agua, la luz y el aire a las casas ocupadas sobre todo por jornaleros y menesterosos, dada la menor cuantía de sus alquileres. A su vez, las clases acomodadas, los comercios y las industrias se ubicaban preferentemente en los distritos de mejores condiciones higiénico-urbanísticas y en algunos de los intermedios.

De los testimonios de la época expuestos, parece desprenderse la existencia de una opinión generalizada sobre la mala situación higiénico-sanitaria de Madrid y de buena parte de sus distritos en el tránsito del siglo XIX al XX. De hecho, este tema fue objeto de mi atención anteriormente, aunque me limité entonces a abordar tan sólo la situación de la capital ${ }^{15}$. Pues bien, teniendo todo esto en cuenta, mi trabajo actual va a consistir en contrastar la información contenida en dichos testimonios y en los estudios historiográficos realizados hasta ahora con la proporcionada por el examen de las variaciones registradas en la mortalidad de los distritos de Madrid. Con ello pretendo hacer un acercamiento a su estado higiénico-sanitario entre $1880 \mathrm{y}$ 1931, utilizando como principales fuentes las Estadísticas Demográfico-Sanitarias ${ }^{16}$. No obstante, el cambio que se produjo en la división administrativa de Madrid en 1903 y la disponibilidad de datos me obliga a restringir el análisis de la mayoría de los indicadores demográficos al período comprendido entre 1903 y 1931. El estudio

14 HAUSER, Ph. (1979), vol. 1, pp. 314-321 y 333-334; vol. 2, pp. 51-53, 66-67, 130-131 y 532. De la desigualdad de los barrios madrileños habían advertido ya CASAS BATISTA, R. (1874), El problema relativo al hogar del obrero, tanto considerado por sí mismo como en su historia a través de la sucesión de edades y los pueblos y MÉnDEZ Álvaro, F. (1874), De la habitación del menesteroso considerado bajo el aspecto higiénico-social. Ambos textos corresponden a los Discursos pronunciados en la Real Academia de Medicina de Madrid para la recepción pública del académico D. Rogelio Casas de Batista el día 11 de enero de 1874, Madrid, Sucs. Rojas.

15 PORRAS Gallo, Ma I. (1996a), «Evolución de la mortalidad de Madrid en el período 1883-1925: una aproximación a la realidad sanitaria que conoció Philiph Hauser», en CARRILlO, J.L. (ed.), Entre Sevilla y Madrid: Estudios sobre Hauser y su entorno, Sevilla, A. Pinelo, pp. 101-129.

16 Concretamente, los datos los he obtenido fundamentalmente de los Anuario Estadístico Demográfico de los años 1897, 1898 y 1899, y de las Estadísticas Demográfico-Sanitarias. Resumen General de 1900 a 1931 (excepto 1902), del Ayuntamiento de Madrid. Para completar los datos relativos a los nacimientos y a las defunciones registrados desde 1880 hasta 1889 me he servido del Boletín de Sanidad (t. 5 , p. 106) del Ministerio de la Gobernación; mientras que para el período comprendido entre 1889 y 1900 he empleado las tasas brutas de mortalidad de Hauser (1979: vol. 2, p. 42), y las cifras proporcionadas por Revenga (1901, p. 9) sobre los nacimientos habidos entre 1890 y 1895, siendo consciente del nivel de subjetividad que pudiera estar presente en los datos de estos dos últimos autores. 
se ha centrado en el análisis de las modificaciones habidas en la mortalidad general e infantil, y en las tasas específicas de algunas enfermedades: concretamente, diarrea y enteritis en menores de dos años, viruela, difteria, tuberculosis pulmonar, gripe y resto de enfermedades respiratorias de los distintos distritos madrileños. La elección de estos procesos ha tenido un doble motivo: por un lado, el hecho de ser los problemas fundamentales que presentaba Madrid en el tránsito del siglo XIX al XX; y, por otro, su condición de indicadores sociales y/o sanitarios ${ }^{17}$.

De cara a sistematizar la exposición, se presentará en un primer momento lo referente a la mortalidad general, a continuación se ofrecerá lo relativo a la mortalidad infantil, y, en último lugar, la atención se centrará en la mortalidad provocada por las enfermedades anteriormente enunciadas. En todos los casos, la presentación de los datos correspondientes a la villa de Madrid en su conjunto precederá normalmente a la de los diferentes distritos madrileños. Respecto a esta última cuestión, interesa recordar muy brevemente que el Madrid estudiado por Hauser se componía de los distritos de Palacio, Universidad, Centro, Hospicio, Buenavista, Congreso, Hospital, Inclusa, Latina y Audiencia (Plano 1), pero que en 1903 entró en vigor una nueva división (Plano 2) ${ }^{18}$. Como resultado de ella, desapareció el distrito de Audiencia y se creó el de Chamberí19.

\section{VARIACIONES REGISTRADAS EN LA MORTALIDAD GENERAL}

Una primera valoración sobre la situación higiénico-sanitaria de los distritos madrileños se puede obtener observando la evolución del crecimiento vegetativo en el período estudiado. Como se ve en la tabla 1, los valores fueron frecuentemente negativos en la mayoría de ellos, observándose en algunos un cambio de tendencia a partir de 1920. De este comportamiento se alejaron, sin embargo, Buenavista, Chamberí

17 Al igual que Méndez Álvaro y Revenga, Hauser consideraba que los principales problemas sanitarios que Madrid tenía eran la tuberculosis pulmonar, los procesos respiratorios y la viruela. HAUSER, Ph. (1979), vol. 2, pp. 43, 126 y 128; MÉndeZ Álvaro, F. (1882), p. 9; y ReVENGA, R. (1901), pp. 4142. A ellos había que añadir la elevada mortalidad infantil. UlECIA CARDONA, R. (1903), Informe acerca de la mortalidad infantil de Madrid: sus principales causas y medios de combatirla, Madrid, Impr. Municipal; y Botella Y MARTíneZ (1903), De la asistencia a la embarazada pobre en Madrid, Madrid, Impr. Romero.

18 Esta nueva división administrativa había sido aprobada el 15 de julio de 1898 , aunque no se acordó su aplicación hasta el 12 de noviembre de 1902. Delimitaciones Municipales Históricas 1768-1955, Boletín Estadístico Municipal, 9, febrero de 1988.

19 El distrito de Audiencia desapareció al incorporarse parte de él al de Centro, otra parte al de Congreso, otra al de Inclusa y el resto al de Latina. A su vez, el barrio de Chamberí, que era uno de los que pertenecían al distrito de Hospicio, se desmembró de él y se constituyó en distrito independiente. Delimitaciones Municipales Históricas 1768-1955, Boletín Estadístico Municipal, 9, febrero de 1988. 
y Latina. De hecho, en los tres casos el balance fue fundamentalmente positivo salvo en los años en los que, como se mostrará más adelante, la aparición de algunas epidemias -viruela y gripe, sobre todo-, provocó un exceso de mortalidad que no pudo ser compensado con la natalidad. De modo que, como fue apuntado por $\operatorname{Hauser}^{20}$ y Chicote $^{21}$ y ha sido puesto de relieve en los recientes estudios historiográficos ${ }^{22}$, parece confirmarse esa desigualdad frente a la enfermedad asociada, al menos en parte, a la estratificación horizontal higiénico-urbanística y socio-económica de Madrid ligada a su división administrativa.

Tampoco mejora nuestra opinión sobre las condiciones de Madrid cuando se examina la evolución de la mortalidad general. La gráfica 1 pone de relieve las altas tasas registradas en los últimos años del siglo XIX, que, en ocasiones, fueron más del doble del valor correspondiente a $1931(17,02 \%)$. Estas cifras, según Lasbennes, mayores que las de la mayoría de las ciudades europeas ${ }^{23}$, además, eran superiores a las de España (Gráfica $2^{24}$ ), salvo en 1918. No obstante, al igual que ocurrió en la mayor parte de nuestro país, a partir de 1900 se inició un descenso de la tasa bruta de mortalidad, que se vio interrumpido tan sólo por la sobremortalidad epidémica de algunos años: las epidemias de viruela de 1909 y 1918, y las de gripe de 1918-19 y 1919-2025. De hecho, no fue hasta 1921 cuando dicho descenso fue más mantenido y las cifras comenzaron a acercarse a las del conjunto de España.

20 Como hemos visto, para este autor, los mejores distritos eran Centro, Congreso y Buenavista, los peores Inclusa, Hospital, Latina y Universidad, mientras que Audiencia, Palacio y Hospicio ocupaban una posición intermedia. HAUSER, Ph. (1979), vol. 2, p. 532.

21 Este autor señaló la mortalidad diferencial de los distintos barrios de Madrid y la relacionó fundamentalmente con el grado de insalubridad de las viviendas. CHICOTE, C. (1914), La vivienda insalubre en Madrid, Madrid, Impr. Municipal, pp. 25-88.

22 Entre los trabajos realizados cabe citar el de Antonio Fernández. Este autor, atendiendo a los valores de las tasas brutas de mortalidad de 1916, ha señalado que las mejores condiciones correspondían a Centro, Hospicio, Buenavista y Palacio, y las peores a Universidad, Hospital e Inclusa; mientras que en un nivel intermedio se hallaban Chamberí, Congreso y Latina. FERNÁNDEZ GARCíA, A. (1989), «La población madrileña entre 1876 y 1931. El cambio de modelo demográfico», en: BAHAMONDE MAGRO, A. \& OTERO CARVAJAL, L.E. (eds.), La sociedad madrileña durante la Restauración. 1876-1931, Madrid, CAM-Alfoz, vol. 1, 29-76, p. 59.

23 De 1903 a 1910, como indicó Lasbennes, tan sólo las tasas brutas de mortalidad de Moscú y, a veces, las de San Petersburgo fueron superiores a las de Madrid. LASBENNES, L. (1912), Mortalidad de Madrid comparada con la de las demás capitales de Europa, Madrid, Impr. Municipal, pp. 18 y 32-33. Con anterioridad, Méndez Álvaro señaló que la mortalidad de Madrid era más o menos el doble de la correspondiente a Londres y a París. MÉNDEZ ÁlVARO, F. (1882), p. 9.

24 Gráfica tomada de ECHEVERri DÁvilA, B. (1993), La Gripe Española. La pandemia de 19181919, Madrid, CIS-Siglo XXI, p. 65.

25 Mayor información sobre las repercusiones demográficas de estas epidemias, puede encontrarse en: Porras Gallo, Ma I. (1996b), Una ciudad en crisis: La epidemia de gripe de 1918-19 en Madrid, Barcelona, ETD micropublicaciones, pp. 198-278; PORRAS GALLO, Ma I. (1996c), «Las repercusiones de la pandemia de gripe de 1918-19 en la mortalidad de la ciudad de Madrid», Boletín de la Asociación de 
Por lo que se refiere a la evolución de la mortalidad general de cada uno de los distritos madrileños, es preciso indicar que, como se aprecia en la gráfica 3 , se ajusta en líneas generales a la tendencia comentada, salvo en el caso de Congreso. Este distrito, partiendo de unos valores inferiores a los de Madrid en su conjunto - comparables a los de los distritos más favorecidos- , registró una elevación de sus tasas hasta acercarse en 1923 a las muy superiores de Hospital e Inclusa, superándolas incluso en 1925 y 1929. Este comportamiento de Congreso coincidió en el tiempo con un acusado y mantenido descenso de las cifras de Inclusa. Como luego se verá más claramente, de ambos fenómenos parece que fue responsable el traslado de la Inclusa desde su ubicación en Mesón de Paredes a la Maternidad de O'Donnell, que se inauguró en $1925^{26}$.

La gráfica 3 permite también apreciar las diferencias existentes entre el valor de las tasas brutas de mortalidad de cada uno de los distritos madrileños a lo largo del período. Así, las menores cifras correspondieron a Buenavista, Hospicio, Centro y Palacio. A su vez, Chamberí, Universidad y Latina presentaron unas tasas medias muy próximas a las de Madrid en su conjunto, mientras que los valores más altos fueron alcanzados por Hospital e Inclusa.

A la vista de lo dicho hasta ahora, parece evidente que la elevada mortalidad y las malas condiciones higiénico-sanitarias de Madrid fueron una constante de la mayor parte del período analizado ${ }^{27}$. Además, como se ha puesto de relieve, se mantuvo con pequeños cambios la mortalidad diferencial de los distritos madrileños derivada en buena medida de sus distintas condiciones higiénico-urbanísticas y socio-económicas. Como suele ser habitual, esta desigualdad ante la enfermedad adquiría renovada actualidad con cada brote epidémico de cierta entidad que se desarrollaba en la capital del reino. De hecho, durante la pandemia de gripe de 1918-19 se denunció la vulnerabilidad de los trabajadores ${ }^{28}$, y la insalubridad de barrios y viviendas, la crisis de subsistencia y la escasa infraestructura sanitaria de la capital fueron algunos de los factores que los médicos esgrimieron para explicar la magnitud y la gravedad epidémica ${ }^{29}$. Es por eso por lo que parece adecuado considerar el posible papel que las acciones encaminadas a la corrección de estos problemas hayan podido desempeñar de cara a posibilitar el descenso de la mortalidad y la superación -en parte, al menos- de los

Demografia Histórica, 14 (1), pp. 75-116; y PORRAS GALLO, Ma I. (1997), Un reto para la sociedad madrileña: la epidemia de gripe de 1918-19, Madrid, CAM-Ed. Complutense, pp. 49-68.

26 Álvarez Sierra, J. (1952), Los Hospitales de Ayer y de Hoy, Madrid, Artes Gráf. municipales, p. 138.

27 En este sentido, es preciso señalar que Hauser reconoció en 1913 que se habían logrado algunas mejoras en Madrid, pero que su situación higiénico-sanitaria seguía siendo mala. HAUSER, Ph. (1913), La Geografia médica de la Península Ibérica, 3 vols., Madrid, Eduardo Arias, vol. 2, pp. 155-157.

28 Sobre esta cuestión, puede verse PORRAS GALlO, M ${ }^{\text {a }}$ I. (1992), «La epidemia de gripe de 19181919 en la prensa obrera», en HUERTAS, R. \& CAMPOS, R. (coords.), Medicina Social y clase obrera en España (siglos XIX y XX), Madrid, FIM, t. 1, pp. 125-144.

29 Porras Gallo, M ${ }^{\mathrm{a}}$ I. (1996b), pp. 353-439; PORRAS GALlO, Mª I. (1997), p. 108. 
$\mathrm{M}^{\mathrm{a}}$ ISABEL PORRAS GALLO

GRÁFICA 1. TASA BRUTA DE MORTALIDAD EN MADRID

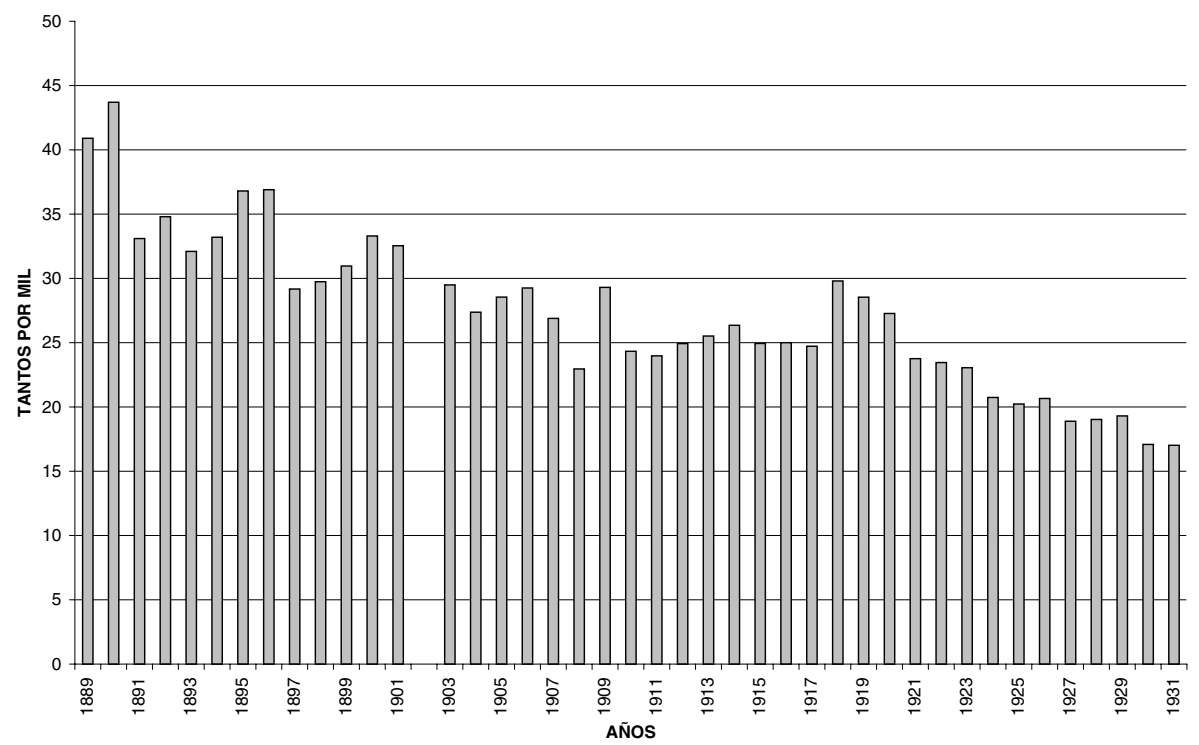

GRÁFICA 2. TASA BRUTA DE MORTALIDAD DE ESPAÑA

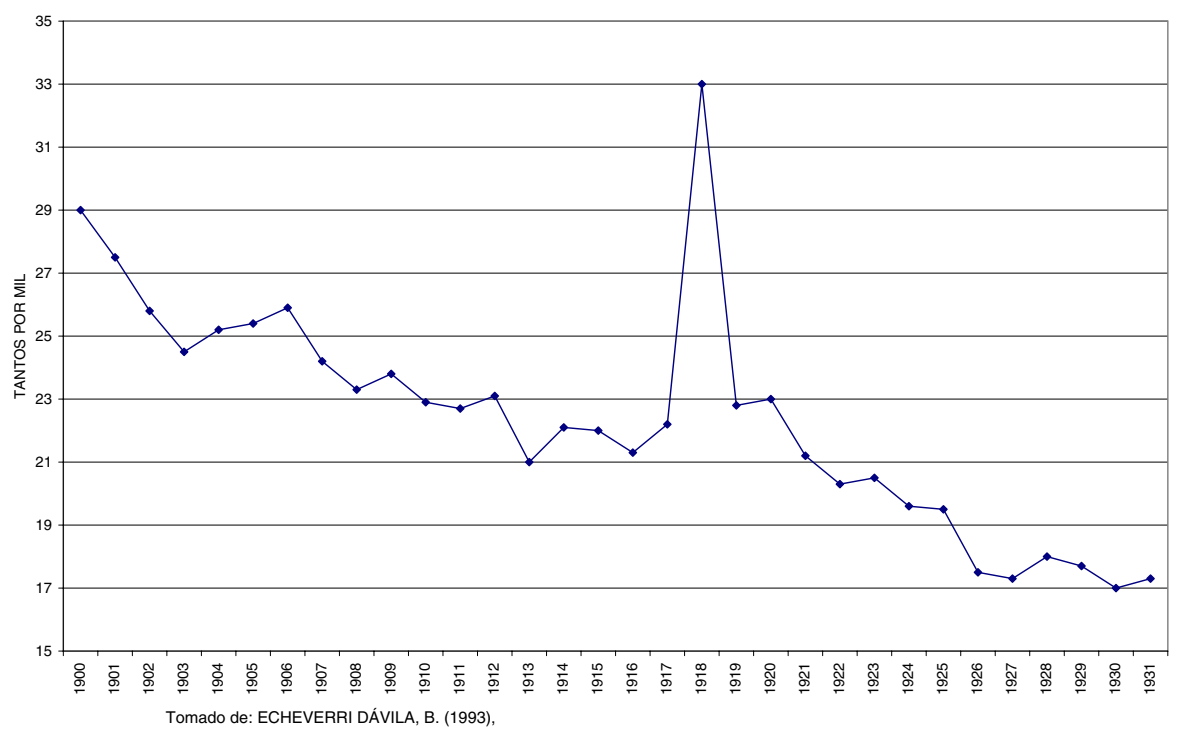


negativos efectos de la urbanización. En este sentido, con independencia de lo que figura más adelante en otros epígrafes, es preciso indicar que, aunque persistieran todavía muchas defíciencias al final del período estudiado, un cambio importante se produjo alrededor de 1918 y, sobre todo, en la tercera década ${ }^{30}$. En efecto, a tenor del contenido de las memorias del Ayuntamiento y del Laboratorio Municipal, así como de las publicaciones del Director del citado laboratorio, parece que a lo largo de ese período se materializaron algunas de las propuestas decimonónicas y de las efectuadas en los primeros años del siglo $\mathrm{XX}^{31}$. De hecho, la modernización progresiva del Laboratorio Municipal desde el cambio de siglo ${ }^{32}$ posibilitó que esta institución adquiriera un papel cada vez más relevante en la lucha contra las enfermedades infecciosas ${ }^{33}$ y en el

30 En opinión de Rueda Laffond, la situación higiénico-urbanística de Madrid cambió a partir de 1918, configurándose la ciudad moderna desde esa fecha hasta 1936. RUEDA LAFFOND, J. C. (1993), «El desarrollo de la ciudad y la política urbanística», en FERnÁNDEZ GARCíA, A. (dir), Historia de Madrid, Madrid, Ed. Complutense, pp. 579-601. Esta situación ha sido señalada también por JULiÁ, S., RINGROSE, D. \& SegurA, C. (1994), Madrid. Historia de una capital, Madrid, Alianza Editorial, p. 305. Una visión sintética y global relativa a la evolución registrada en la manera de abordar la higiene local desde el siglo XIX al XX, la ofrece PERDIGUERo GIL, E. (1997), «Problemas de salud e higiene en el ámbito local». en Bernabeu Mestre, J.; Espluges i Pellicer, J. X. \& Robles GonzÁlez, E. (eds.), Higiene $i$ Salubritat en els municipis valencians, Benissa, Seminari d'Estudis sobre la Ciència. Institut d'Estudis Comarcals de la Marina Alta, pp. 17-41.

31 Además de las fuentes citadas anteriormente, sobre las deficiencias higiénico-urbanísticas madrileñas y mejoras reclamadas durante el tránsito del siglo XIX al XX, pueden consultarse: Memoria de la Junta Municipal de Sanidad de Madrid para dar cumplimiento a lo preceptuado en la Real orden de 20 de Marzo de 1894, emanada del Ministerio de la Gobernación, Madrid, Impr. Municipal, 1894. «Las Ordenanzas municipales de Madrid», El Siglo Médico, [2223, 2 de agosto de 1896, pp. 481-483; y 2224, 17 de agosto de 1896, pp. 499-502]; OldAMONT (1901), La Higiene Pública en España, Madrid, Ed. A. de San Martín; REAL CONSEJO DE SANIDAD (1901), Sanidad Cuestiones fundamentales de Higiene Pública en España, Madrid, E. Teodoro; CABELlo LAPIEDRA, L.M (1905), Baños-duchas populares de la Villa de Madrid, Madrid, A. Marzo; CHicote, C. (1906), Reorganización del Servicio de limpieza de Madrid, informe elaborado a la Alcaldia Presidencia, Madrid, Impr. Municipal; y MELGosA, M. (1912), Las subsistencias en Madrid, Madrid.

32 Para obtener información sobre las mejoras realizadas en el Laboratorio Municipal en los dos primeros años del siglo XX, véase: CHICOTE, C. (1901), El Servicio municipal de Desinfección en Madrid, Madrid, T. Osácar.

33 De hecho, durante la pandemia de gripe de 1918-19 se puso de relieve su competitividad en lo que a aislamiento del germen y preparación de sueros y vacunas se refería. PORRAS GALLO, M ${ }^{\mathrm{a}}$ I. (1997), «El Laboratorio Municipal de Madrid y la epidemia de gripe de Madrid de 1918-19», Anales del Instituto de Estudios Madrileños, 37, pp. 585-591. Sin embargo, esta modernización había sido un proceso largo. Así, la preparación del suero antidiftérico que debería haberse iniciado en 1899 no comenzó hasta 1911, y fue hacia mediados de la segunda década del siglo cuando comenzó a tener una mayor capacidad para hacer frente a las enfermedades infecciosas. FRANCOS RODRÍGUEZ, J. (1911), Memoria de la Gestión del Excelentísimo Ayuntamiento de Madrid. 1 de Julio de 1909 a 30 de Septiembre de 1911, Madrid, Impr. Municipal, p. 114. Una visión más general, figura en: CHICOTE, C. (1916), Las vacunas y los sueros del Laboratorio municipal, Madrid, Impr. Municipal. 
GRÁFICA 3. TASA BRUTA DE MORTALIDAD DE MADRID Y SUS DISTRITOS

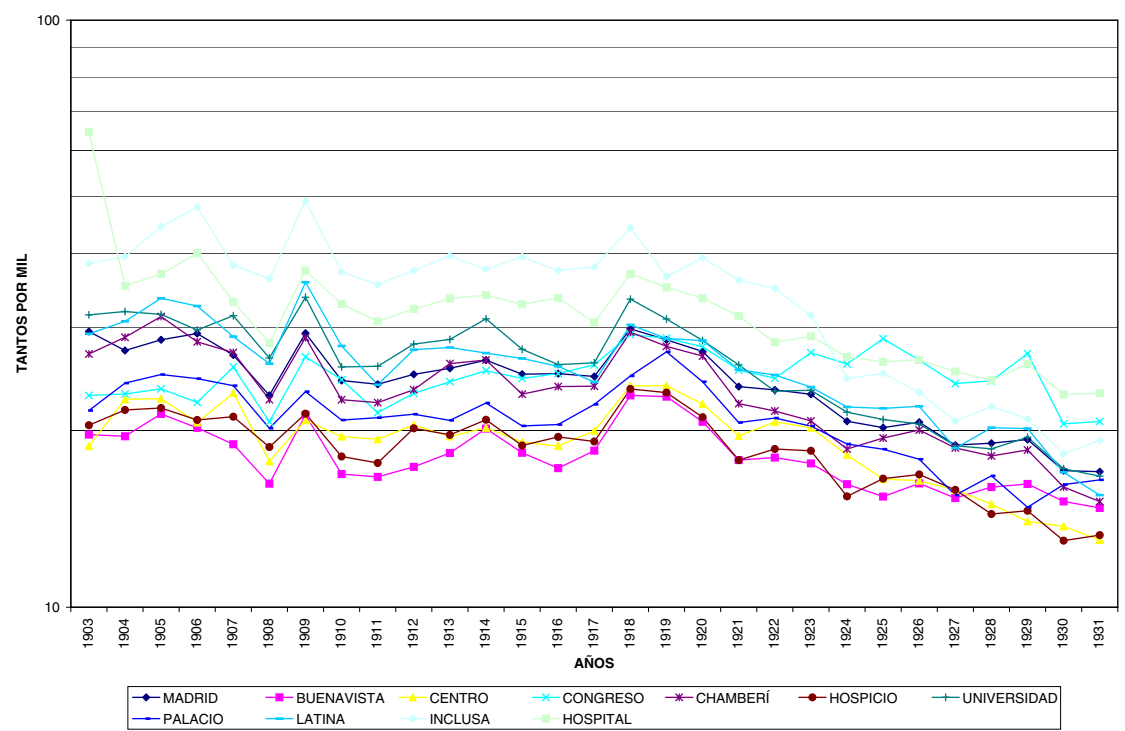

GRÁFICA 4. MORTALIDAD INFANTIL LEGAL DE MADRID Y ESPAÑA

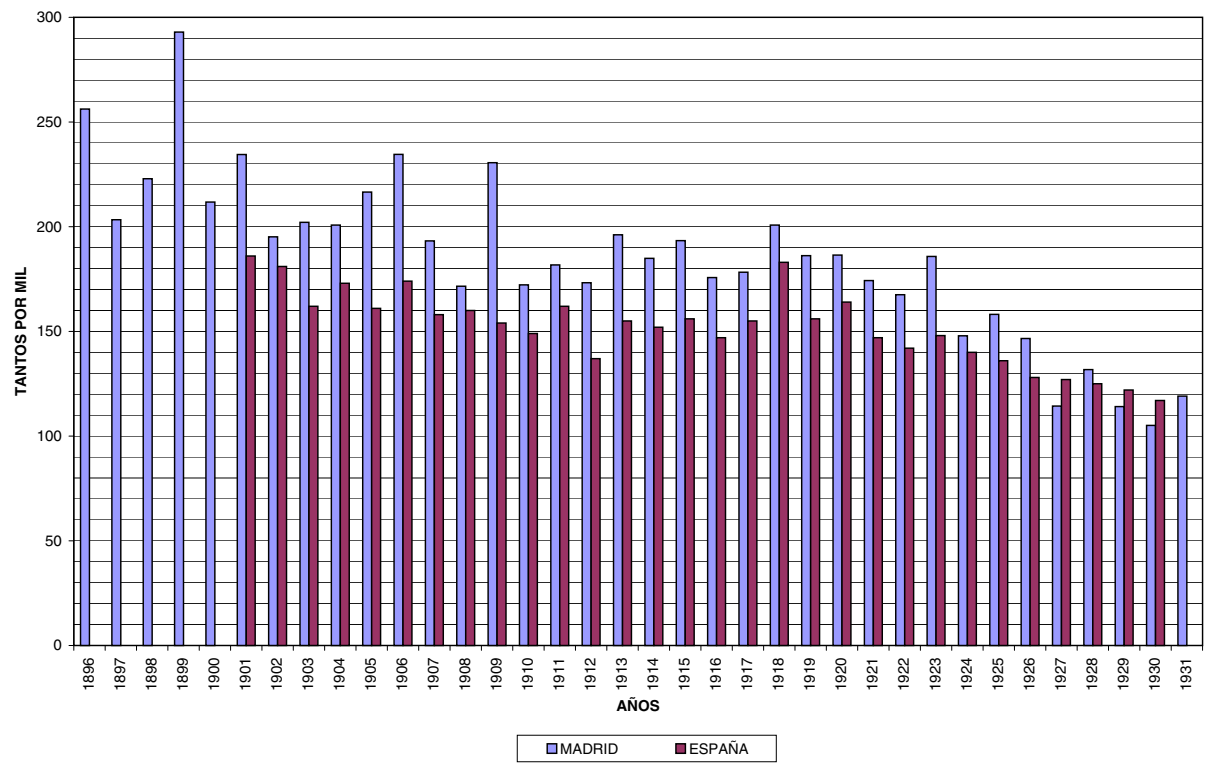


control de la calidad de los alimentos ${ }^{34}$. La reorganización del Servicio de limpieza solicitada por Chicote en 1906 no se inició hasta 1921, de modo que hasta entonces los cambios en cuanto a la limpieza de la ciudad, recogida y eliminación de basuras fueron escasos ${ }^{35}$. Otras mejoras higiénicas, como la construcción de evacuatorios, urinarios y baños populares, fueron llevándose a cabo a lo largo de la segunda y tercera década ${ }^{36}$. También se realizó un esfuerzo importante para solucionar el problema del abastecimiento de agua a los barrios altos de la capital, así como para ir aumentando la red de alcantarillado de la ciudad. Así, los $95 \mathrm{Km}$. existentes en 1912 se convirtieron en $540 \mathrm{Km}$. en $1927^{37}$. No obstante, a pesar de estas transformaciones que se habían operado, Chicote consideraba en 1930 que, de cara a mejorar las condiciones de salubridad de Madrid, las actuaciones municipales deberían tener como principales objetivos: ampliar la dotación de agua, cuidando de su abundancia y pureza; continuar la obra del alcantarillado; perfeccionar los servicios de limpieza pública y alejamiento de basuras; y, sobre todo, atender al problema de la vivienda insalubre ${ }^{38}$.

\section{EVOLUCIÓN DE LA MORTALIDAD INFANTIL Y DE LA MORTALIDAD POR DIARREA Y ENTERITIS EN MENORES DE 2 AÑOS}

La aterradora sobremortalidad infantil fue otro de los rasgos característicos de Madrid en el tránsito del siglo XIX al XX, siendo numerosos los pediatras e higienistas que, en conexión con el marcado protagonismo social que este tema alcanzó dentro de nuestras fronteras ${ }^{39}$, denunciaron dicha situación ${ }^{40}$. Al igual que hicieran sus

34 Chicote, C. (1913), Laboratorio. Resumen de los trabajos efectuados durante el año 1912, Madrid, Impr. Municipal, pp. 4-7.

35 Chicote, C. (1921), El servicio de limpieza, Madrid, Jaime Ratés.

36 Francos RODRÍGUEZ, J. (1911), p. 66.

37 Chicote Riego, C. (1927), Discurso leido en la solemne Sesión inaugural del curso de 1928 en la Real Academia Nacional de Medicina, Madrid, Impr. Julio Cosano, pp. 19-24.

38 Chicote, C. (1930), El progreso sanitario de Madrid, Madrid, Impr. Municipal, st. pp. 11-12. Sobre el problema de la vivienda, véase HuERTAS, R. (2002), «Vivir y morir en Madrid. La vivienda como factor determinante del estado de salud de la población madrileña, 1874-1923», Asclepio, 54-2, 2002 (e. p.)

39 El hecho de que en el Congreso médico internacional de Sevilla de 1882 se debatiera sobre las «Causas de la excesiva mortalidad de la primera infancia en las grandes ciudades y medios atenuarla», nos puede dar una idea de la importancia que este tema estaba adquiriendo en las postrimerías del siglo XIX. RODRÍGUEZ OCAÑA, E. (1985), «Aspectos sociales de la pediatría española anteriores a la Guerra Civil (1936-39)», en PESET, J.L. (ed.), La ciencia moderna y el nuevo mundo, Madrid, C.S.I.C., 443-460, p. 444. Más información sobre esta cuestión figura en: RODRÍGUEZ OCAÑA, E. (1986), «Medicina y acción social en la España del primer tercio del siglo XX», en De la Beneficencia al bienestar social. Cuatro siglos de acción social, Madrid, Siglo XXI-CGCODTSAS, 227-265, pp. 233-245; RODRÍGUEZ 
contemporáneos, Rafael Ulecia (1850-1912) llamó también la atención sobre la «enorme» - $\mathrm{y}$, en buena medida, «evitable»- cantidad de «niños menores de cinco años» que perdía anualmente Madrid. De hecho, según el citado autor, entre 1896 y 1902 , este sector de la población había representado el $40 \%$ del total de defunciones, constituyendo los menores de 1 año algo más del $22 \%{ }^{41}$.

En efecto, como permite ver la gráfica 4, las denuncias parece que se correspondían con la realidad imperante. De hecho, las tasas de mortalidad infantil de Madrid fueron casi siempre superiores a las del conjunto de España ${ }^{42}$. Esta tendencia se invirtió en 1927, siendo desde ese momento las tasas madrileñas menores generalmente. En cuanto a la evolución a lo largo del período estudiado, cabe decir que, al igual que ocurrió en el resto de nuestro país, las disminuciones registradas en los primeros años del siglo XX se alternaron con algunas elevaciones epidémicas ${ }^{43}$, no alcanzándose un descenso mantenido de las cifras hasta mediados de la tercera década ${ }^{44}$. Este comportamiento coincide igualmente con lo sucedido en el medio rural madrileño ${ }^{45}$, si bien

OCAÑA, E. \& MOlero MesA, J. (1993), «La cruzada por la salud. Las campañas sanitarias del primer tercio del siglo XX», en MONTIEL, L. (coord.), La salud en el Estado de Bienestar. Análisis histórico, Madrid, Edit. Complutense, pp. 133-148; BAllester, R. \& BAlAGUER, E. (1995), «La infancia como valor y como problema en las luchas sanitarias de principios de siglo en España», Dynamis, 15, pp. 177192; y BORRÁS LLOP, J.M. (1996), Historia de la infancia en la España contemporánea (1834-1936), Madrid, Ministerio de Trabajo y Asuntos Sociales-Fundación Germán Sánchez Ruipérez.

40 Entre ellos cabe señalar a IGLESIAS DÍAZ, M. (1883), «Algunos datos estadísticos sobre defunciones y nacimientos en Madrid de 1748 a 1839», El Siglo Médico, 1529, p. 277; AGUIRRE BARRIO, J. (1885), Mortalidad de la primera infancia, sus causas y medios de atenuarlas, Madrid; JIMENO AGIÚS, J. (1886), p. 66; SILIÓ CORTÉS, C. (1897), Los que nacen y los que mueren, Valladolid, p. 26; HAUSER, Ph. (1979), vol. 1, pp. 534-536; FATÁs MONTES, L. (1903), La mortalidad de los niños en Madrid: causas y remedios, Madrid, E. Teodoro; y UlECIA CARDONA, R. (1903).

41 Ulecia CARDONA, R. (1903), p. 15. En 1927, los menores de 5 años constituían el 35\% de las defunciones. BRAVO FríAS, J. (1927), Mortalidad infantil en Madrid y medios para aminorarla, Madrid, p. 13.

42 Para el caso de España, me he servido de las tasas de mortalidad infantil de 1901 a 1930 proporcionadas por PASCUA, M. (1934), La mortalidad infantil en España, Madrid, Departamento de Estadística de la Dirección General de Sanidad, p. 22.

43 Según las Estadísticas municipales, responsables de las principales elevaciones epidémicas (1905, 1906 y 1909) fueron la diarrea infantil, la bronquitis aguda y la viruela. Esta última tuvo especial peso en 1909.

44 Sobre lo acaecido en España, pueden consultarse: GÓMEZ REDONDO, R. (1992), La mortalidad infantil española en el siglo XX, Madrid, CIS-Siglo XXI, pp. 63-65 y 227-230; REHER, D. S., PÉREZMoredA, V. \& Bernabeu-Mestre, J. (1997), «Assessing Change in Historical Contexts: Childhood Mortality Patterns in Spain during the Demographic Transition», en The Decline of Infant and Child Mortality, Unicef, pp. 35-56; y BALAGUER PERIGÜELL, E. et al. (1992), «La transición sanitaria española en el período 1879-1919», en LIVI BACCI, M. (coord.), Modelos regionales de la transición demográfica en España y Portugal, Alicante, I. J. Gil Albert, pp. 137-156.

45 Información relativa a esta cuestión figura en SANZ GIMENO, A. (1999), La mortalidad de la infancia en Madrid. Cambios demográfico-sanitarios en los siglos XIX y XX, Madrid, Comunidad de Madrid, pp. 52-70 y en su tesis: SANZ GIMENO, A. (1997), La transición de la mortalidad infantil y juvenil en el Madrid rural. Siglos XIX y XX, Universidad Complutense de Madrid (Tesis doctoral inédita). Respecto a la evolución de la mortalidad infanto-juvenil en la capital y otros puntos de nuestro país, resulta muy interesante la 
es preciso señalar que la mortalidad infantil de la capital superó a la del mundo rural a lo largo de todo el período estudiado ${ }^{46}$.

Esta tendencia descendente fue también la tónica general de todos los distritos de Madrid, salvo Congreso. Como muestra la gráfica 5, este distrito registró una elevación brusca de su tasa de mortalidad infantil en 1923 que se mantenía al término del período analizado, aunque había disminuido algo su valor. Coincidiendo en el tiempo con este fenómeno, se produjo un descenso muy acusado de las cifras de Inclusa. La explicación de estos hechos tenemos que buscarla, como señalé más arriba, en el traslado de la Inclusa de su local de Mesón de Paredes a la moderna Maternidad de O'Donnell, inaugurada oficialmente en $1925^{47}$. Dada la importancia que la sobremortalidad infantil tenía de cara a explicar la elevada mortalidad general de la capital ${ }^{48}$, es por lo que, además, como he indicado también anteriormente, este mismo fenómeno se produjo en la distribución de la tasa bruta de mortalidad por distritos.

Como se puede apreciar en la gráfica 5, las diferencias existentes en cuanto a los valores registrados en cada uno de los distritos madrileños se fueron reduciendo a lo largo de las primeras décadas del siglo XX. No obstante, en los primeros años, Buenavista, Hospicio, Centro, Palacio y Congreso poseían las tasas más bajas, mientras que las más elevadas correspondían claramente a Inclusa — en un primer momentoy más tarde a Congreso. El resto de los distritos tuvieron unos valores intermedios, próximos a los de Madrid en su conjunto. Una vez más se aprecia la correlación existente entre la mortalidad diferencial de los distritos madrileños y la estructuración horizontal socio-económica e higiénico-urbanista, observándose también el peso que la presencia en la capital de algunas instituciones benéfico-asistenciales tenía a la hora de incrementar algunas de sus tasas de mortalidad.

A la hora de explicar la elevada mortalidad infantil e infanto-juvenil, higienistas y pediatras coincidieron en señalar a la diarrea como principal responsable ${ }^{49}$. Pues bien,

reciente aportación de DOPICO GUTIERREZ Del ARROYo, F. y REHER, D. (1998), El declive de la mortalidad en España, 1860-1930, Zaragoza, Monografías I de la Asociación de Demografía Histórica.

46 Sobre este tema, véase SANZ GIMENO, A. (1999), pp. 76-81. Este autor ha señalado 1930 como el momento en que la hipermortalidad urbana dio paso a la sobremortalidad rural en Madrid, mientras que Gómez Redondo sitúa dicho paso para España en torno a 1926. GómEZ REDONDO, R. (1992), pp. 186-192.

47 Álvarez SierRA, J. (1952), p. 138.

48 Este fenómeno ha sido señalado recientemente por PÉREZ MOREDA, V. (1991), «La población de la ciudad de Madrid, siglos XVIII al XX», en Visión Histórica de Madrid (Siglos XVI al XX), Madrid, Real Sociedad Económica Matritense de Amigos del País, 183-213, p. 195.

49 En este sentido se manifestó Ulecia, aun cuando la principal causa de muerte era la bronquitis aguda. El citado autor justificaba mediante una enrevesada argumentación esa aparente contradicción, y relacionaba la diarrea con deficiencias en la lactancia, alimentación prematura y otras infracciones dietéticas. UleCIA, R. (1903), pp. 16, 21-22. Junto a los factores citados, otros autores han señalado el papel que tenían también las malas condiciones medioambientales y algunas prácticas populares asociadas con la dentición. BERNABEU-MESTRE, J. (1994), «Problèmes de santé et causes de décès infantiles en Espagne», Annales de Démographiques Historique, 61-77, pp. 65 y 67-73. 
GRÁFICA 5. MORTALIDAD INFANTIL LEGAL DE MADRID Y SUS DISTRITOS

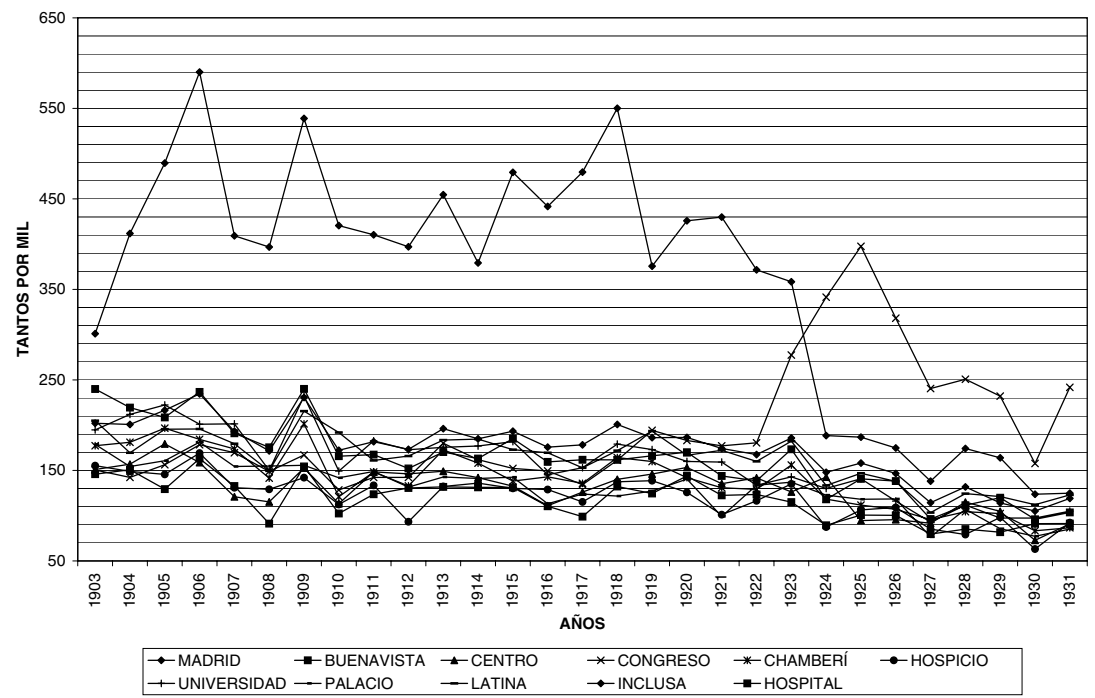

GRÁFICA 6. MORTALIDAD POR DIARREA Y ENTERITIS EN MENORES DE DOS AÑOS

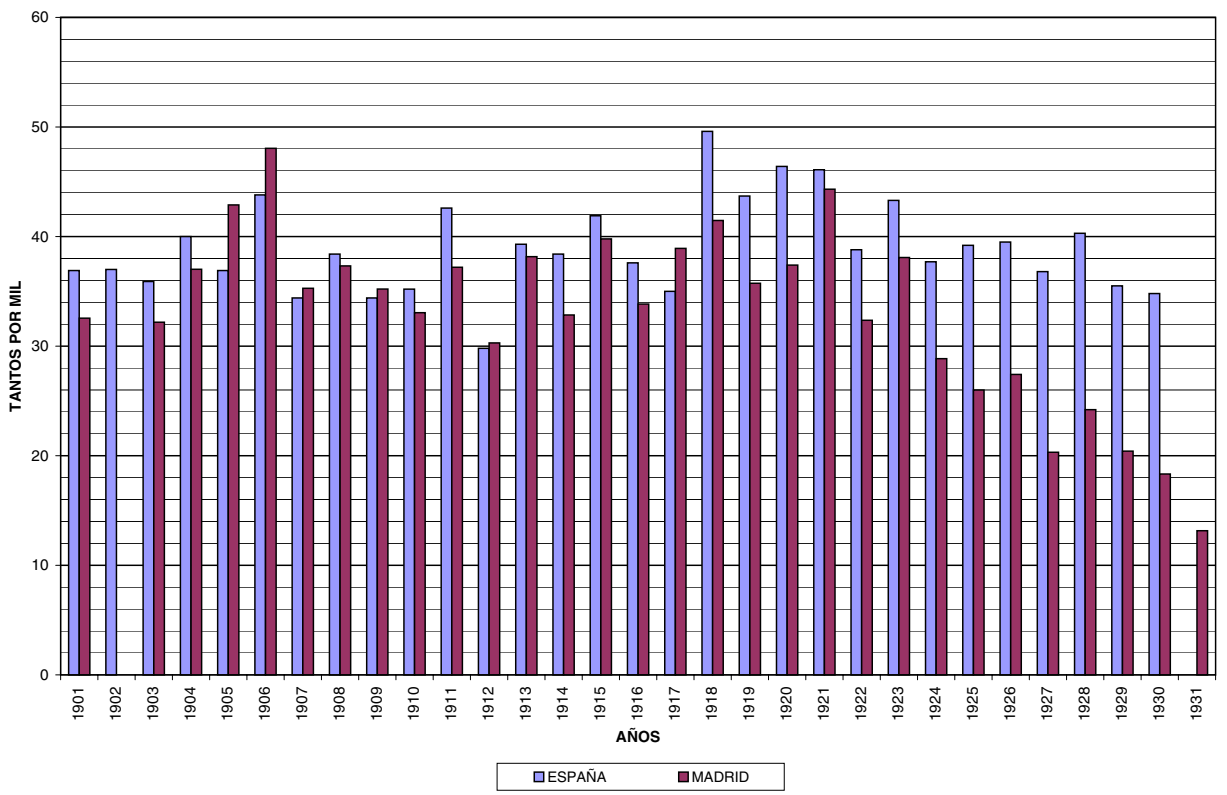


la gráfica 6 permite ver las altas tasas de mortalidad por diarrea y enteritis en menores de 2 años que se alcanzaron en los primeros años del siglo XX en la ciudad de Madrid, pero también pone de relieve cómo estos valores eran inferiores a los de España ${ }^{50}$. Igualmente, se puede observar el tímido descenso que se inició en 1907 y que se alternó con algunas elevaciones. La disminución se hizo más marcada en la segunda mitad de la tercera década, especialmente desde 1924, siendo particularmente acusada al comenzar los años treinta. Así, los valores de $1930(16,03 \%$ ) y 1931 $(15,33 \%)$ son inferiores en más de un $50 \%$ a los registrados en la primera década del presente siglo. Esta situación contrasta con lo ocurrido en España, y con lo acaecido en el medio rural madrileño ${ }^{51}$. Aunque no contamos con las tasas desagregadas por distritos, la distribución porcentual (Gráfica 7) muestra una vez más las desigualdades existentes, correspondiendo los mayores porcentajes a Inclusa y los menores a Hospicio, Centro y Palacio. Igualmente se puede apreciar cómo el descenso fue general en todos los distritos a partir de 1924.

La evolución de la mortalidad infantil y la debida a una de sus principales causas - diarrea y enteritis en menores de 2 años- corroboran los testimonios referentes a la mala situación de la mayoría de los distritos madrileños en el tránsito del siglo XIX al XX, pero ponen también de manifiesto cómo dicha situación cambió, primero de un modo discreto $\mathrm{y}$, a partir de la segunda mitad de la tercera década, más rápidamente. A la hora de explicar este fenómeno, la historiografía reciente acude a la valoración de la posible acción combinada de múltiples factores ${ }^{52}$. En este sentido, uno de los elementos a tener en cuenta serían las discretas mejoras higiénico-urbanísticas que, como he comentado, se efectuaron en Madrid, primero muy lentamente y, de modo más importante, a partir del inicio de la tercera década. Junto a ello habría que considerar el papel que tuvo el cambio de actitud frente a la infancia ${ }^{53}$. La nueva va-

50 PASCUA, M. (1935), p. 35.

51 Sobre este tema, véase SANZ GIMENO, A. (1999), pp. 89-92 y 96-99.

52 Entre las recientes e interesantes aportaciones realizadas en este sentido, figuran: SANZ GIMENO, A. (1999), st. pp. 103-109. SANZ GIMENO, A. (1997). BERNABEU-MESTRE, J. (1994), pp. 61-77; BERNABEU-MESTRE, J. (1995), «Malaltia, cultura i població: factors culturals en l'anàlisi demogràfica i epidemiològica», en BARONA, J. L. (ed), Malaltia i cultura, Vàlencia, Seminari d'Estudis sobre la Ciència, pp. 153-163; BERNABEU MESTRE, J. (1996), «Transición sanitaria y evolución de la Medicina (diagnóstico, profilaxis y terapéutica), 1885-1942», Secondo Convegno dei Giovani Studiosi dei Problemi di Popolazione. Studi di Popolazione. Temi di Ricerca Nuova, 25-27 de junio, Roma, Università di Roma, pp. 131145; RODRÍGUEZ OCAÑA, E. (1995), «La construcción de la salud infantil. Ciencia, medicina y educación en la transición de la mortalidad en España», IV Congreso de la Asociación de Demografía Histórica, 2022 de septiembre, Bilbao-San Sebastián (e.p.); COHEN, A. (1996), «La mortalidad de los niños», y RoDRÍGUEZ OCAÑA, E. (1996), «Una medicina para la infancia», ambos en BORRÁs LlOP, J.M. (dir.), Historia de la infancia en la España contemporánea, 1834-1936, Madrid, Ministerio de Trabajo y Asuntos Sociales-Fundación Germán Sánchez Ruipérez, pp. 109-148 y 149-192.

53 Para tener una idea más completa del alcance que tuvo este cambio de actitud, resulta muy útil la lectura de la bibliografía incluida en la nota 39. 
GRÁFICA 7. DISTRIBUCIÓN PORCENTUAL DE LA MORTALIDAD POR DIARREA Y ENTERITIS EN MENORES DE 2 AÑOS

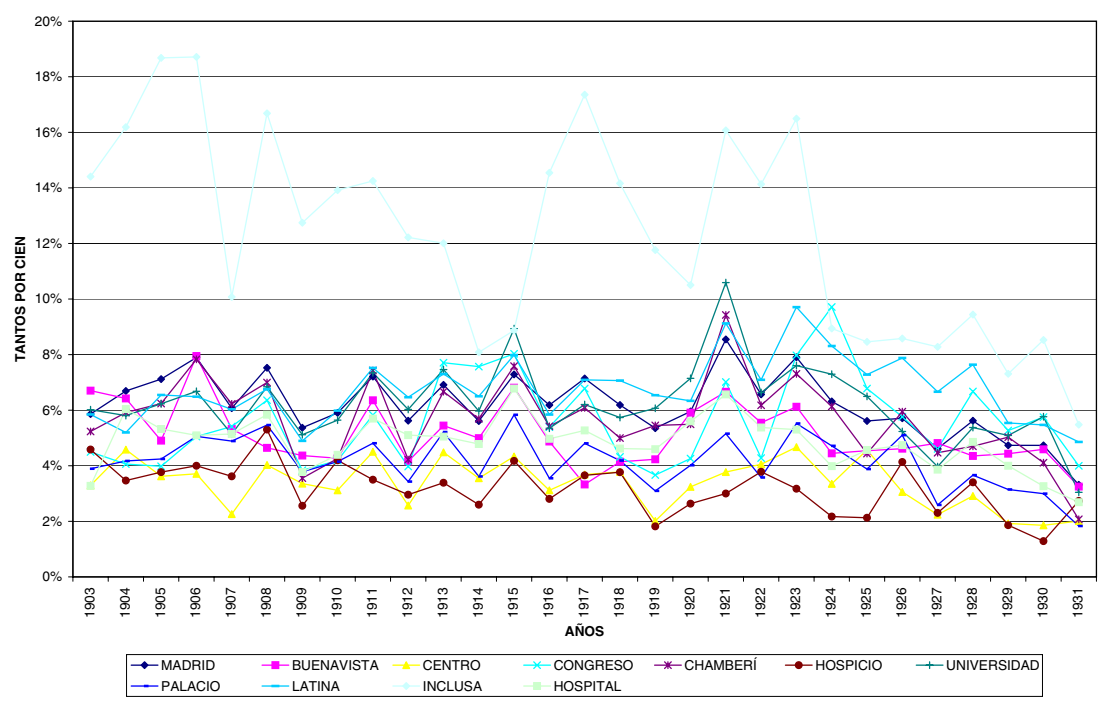

GRÁFICA 8. MORTALIDAD POR VIRUELA, MADRID

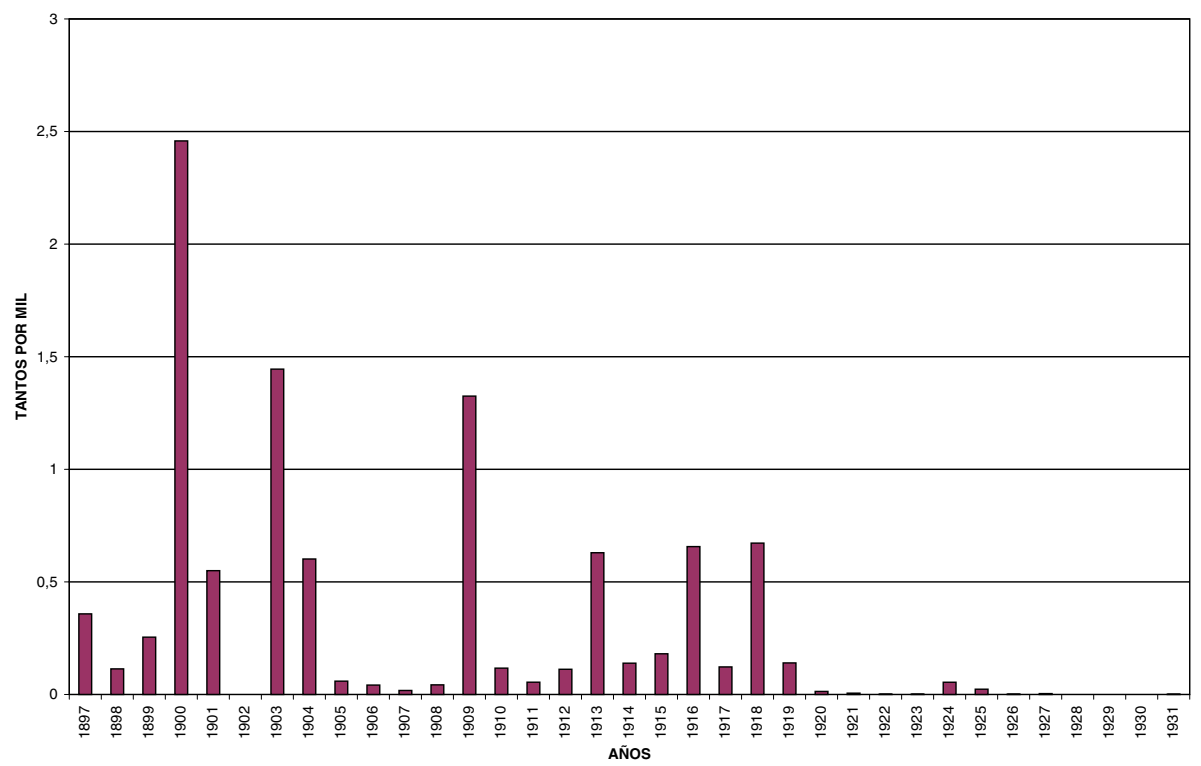


loración del niño se constituyó en motor esencial de una serie de transformaciones que se llevaron a cabo en distintos ámbitos de forma paulatina. En el terreno legislativo, fructificó en la promulgación de la Ley de Protección a la Infancia de $1904^{54}$. En este marco, además de considerar el papel que pudieron tener la aparición y difusión de algunas novedades terapéuticas y profilácticas — sueros y vacunas, principalmente ${ }^{55}$ - , cabe señalar las aportaciones efectuadas desde la Pediatría y su faceta médico-social, la Puericultura, así como mediante los Consultorios para lactantes y Gotas de Leche, que fueron la respuesta institucional de la lucha contra la mortalidad infantil ${ }^{56}$. En el caso de Madrid, esto se tradujo en la puesta en marcha en 1904 del primero de estos Consultorios de Niños de Pecho, organizado por Rafael Ulecia, al que más tarde se sumaron otros, igualmente de iniciativa privada. Con anterioridad, se había empezado a desarrollar también una embrionaria asistencia especializada, que se había plasmado en la fundación del Hospital del Niño Jesús en 1876 y en la dotación de una sala para niños en el Instituto Rubio (ubicado entonces en el Hospital de la Princesa) desde 1884. A ello se añadió posteriormente el establecimiento de los primeros dispensarios en el ámbito de la beneficencia municipal. Así, en 1892 se instaló una Consulta para niños enfermos y pobres en la Casa de Socorro del distrito Centro; y en julio de 1893 otra en los nuevos locales de la Casa de Socorro del distrito de Palacio. En 1913, a partir de este último centro se constituyó la Institución Municipal de Puericultura, en la que se prestaría un conjunto diverso de servicios relacionados con el cuidado de los niños, y en la que, en 1918, se crearían las Escuelas de Maternología ${ }^{57}$. Esta atención especializada a la población infantil se intentó extender al ámbito educativo instituyendo la Inspección Médico-escolar en 1911, aunque su actividad fue escasa o casi nula en los primeros años de andadura, consolidándose entre 1920 y $1930^{58}$. A lo comentado habría que sumar, dentro de la línea tendente a tecnificar la relación madre-hijo, la fundación de la Escuela Nacional de Puericultura en 1923 y el inicio del primer curso en 1926, que permitió el reconocimiento de la Puericultura como actividad especializada. Un importante complemento

54 El origen de esta Ley fueron unas Bases elaboradas por la Sociedad Española de Higiene en 1899. RODRÍGUEZ OCAÑA, E. (1996), p. 152.

55 En este sentido, como luego se verá, uno de los principales elementos a tener en cuenta es el suero antidiftérico. Sobre la introducción y la difusión de este remedio en España, véase: RODRÍGUEZ OCAÑA, E. (1994), «El tratamiento de la difteria en la España de la segunda mitad del siglo diecinueve», Medicina e Historia, 54, pp. 5-28.

56 En la exposición de los datos relativos a este tema, que figura seguidamente, sigo fundamentalmente los trabajos de RODRÍGUEZ OCAÑA, E. de 1985, 1994, 1995 y 1996.

57 Información facilitada por E. Rodríguez Ocaña.

58 BAllester, R. \& BALAguer, E. (1998), «Renovación pedagógica e higiene escolar en la España del primer tercio del siglo XX», en CASTEllanos, J.; JimÉnEZ LUCENA, I.; RUIZ SOMAVILlA, Mª J. \& GARDETA SABATER, P. (coords.) La Medicina en el siglo XX. Estudios históricos sobre Medicina, Sociedad y Estado, Málaga, Sociedad Española de Historia de la Medicina, 241-253, pp. 246-252. 
de lo expuesto, que tuvo un peso considerable en la modificación de los comportamientos y creencias perjudiciales para la salud de los niños, fueron las tareas de educación sanitaria realizadas en medios tan diversos como los Consultorios para lactantes, las Conferencias de maternología y la escuela ${ }^{59}$.

\section{VARIACIONES DE LA MORTALIDAD POR VIRUELA}

Si grave era la aterradora sobremortalidad infantil de Madrid, vergonzoso era lo que sucedía con la viruela. Conforme a los testimonios de la época, esta enfermedad, contra la que existía un remedio eficaz -la vacuna-, estaba presente y era responsable de frecuentes epidemias, siendo la mortalidad por dicha causa importante ${ }^{60}$ y superior a la registrada en los pueblos de la provincia ${ }^{61}$ y en la mayoría de las capitales europeas $^{62}$. En efecto, como muestra la gráfica 8 , la viruela fue una constante hasta $1919^{63}$, alternándose tasas inferiores a $0,50 \%$, correspondientes a los años no epidémicos, con grandes elevaciones en los epidémicos ${ }^{64}$.

Esta situación, que se consideraba un exponente del grado de abandono sanitario en el que se hallaba Madrid y, en general, todo el país, se relacionaba con la indife-

59 La escuela, tal y como han señalado algunos autores, fue un lugar utilizado a partir de la segunda y tercera década de nuestro siglo para enseñar a niños y niñas las principales medidas higiénicas, y también para difundir las nociones de bacteriología en los hogares a través de la enseñanza de economía e higiene doméstica que se proporcionó a las niñas. PERDIGUERO, E. (1994), «Popularización de la higiene en los manuales de economía doméstica en el tránsito de los siglos XIX al XX», en BARONA, J. L. (ed.) Malaltia i cultura, Vàlencia, Seminari d'Estudis sobre la Ciència, 225-250, p. 245; y BALLESTER, R.; PERDIGUERO, E. (1998), «"Levántate temprano, acuéstate pronto y ocupa bien el día”: medicina, higiene y moral en la escuela primaria en España (1857-1936)», en BALLESTER, R. (ed.), La medicina en España y en Francia y sus relaciones con la ciencia, la tradición y los saberes tradicionales (siglos XVIII a XX), Alicante, I. de Cultura «Juan Gil-Albert», pp. 171-196.

60 Méndez Álvaro, F. (1882), pp. 5-6; Hauser, Ph. (1979), vol. 2, pp. 45-53; y HaUSER, Ph. (1913), t. 2, pp. 155-157 y 263 (Conforme a los datos que figuran en esta última página, se puede ver cómo tan sólo había cinco capitales españolas con tasas superiores a la registrada en Madrid durante los años 1900-1906).

61 De hecho, según los datos facilitados por Revenga, la tasa de mortalidad de Madrid era 2,46\% y tan sólo 0,57\% la de los pueblos de la provincia. REVENGA, R. (1901), p. 42.

62 LASBENNES, L. (1912), p. 34, cuadro 3.

63 De hecho, fue responsable del 13\% de las defunciones de 1890, del 8,87\% de las de 1896 y del 7,38\% de las de 1900. PORRAS GALLO, Ma I. (1996a), p. 120. Esta situación contrasta con lo acaecido en Londres, en donde al aumento registrado desde 1860 le siguió una disminución importante a partir de 1885 , lográndose prácticamente su erradicación en 1900. HARDY, A. (1993), The Epidemic Streets. Infectious Disease and the Rise of Preventive Medicine, 1856-1900, Oxford, Clarendon Press, pp. 110-150.

64 De 1901 a 1910, las tasas de Madrid fueron siempre superiores a las registradas en el conjunto de España, que figuran en: MARTín SAlAZAR, M. (1913), La Sanidad en España, Madrid, Impr. Real Colegio de sordomudos y ciegos, p. 140. 
rencia y apatía de las autoridades y de la población frente a la vacunación ${ }^{65}$. De hecho, ésta no fue obligatoria hasta 1903, y tan sólo en caso de epidemia o de recrudecimiento de la endemia ${ }^{66}$. De ahí la importante presencia de la viruela en los primeros años del siglo $\mathrm{XX}^{67}$, siendo especialmente llamativas las epidemias de 1900 , 1903 y $1909^{68}$. No obstante, como se ve en la gráfica 8 , los picos fueron cada vez menos pronunciados, hasta que la situación cambió tras la epidemia de 1918, que coincidió parcialmente con el segundo brote de la pandemia de gripe de 1918-19. A partir de 1920 las defunciones por dicha causa disminuyeron e incluso llegaron a desaparecer, produciéndose únicamente una pequeña epidemia en los años 1924-25, que no alcanzó los niveles anteriores a 1919.

Como se puede comprobar a través de la gráfica 9, la evolución de las tasas de mortalidad de los distintos distritos reproduce el patrón comentado para el conjunto de Madrid. No obstante, se advierte una vez más cómo los valores más elevados de cada pico epidémico correspondían a Hospital, Inclusa, Latina y Universidad, mientras que los menores a Buenavista, Hospicio, Palacio y Chamberí. Responsables de esta desigualdad eran tanto las diferencias higiénico-sanitarias existentes como la mayor o menor presencia de instituciones sanitarias en las que mayoritariamente se acogía a estos enfermos durante los brotes epidémicos.

Los datos que acabo de exponer sobre la mortalidad por viruela y su evolución a lo largo del período estudiado, corroboran también los testimonios relativos a la mala situación higiénico-sanitaria de los distritos madrileños en el tránsito del siglo XIX al XX y a la existencia de una mortalidad diferencial, fruto en buena medida de la estratificación horizontal socio-económica e higiénico-sanitaria asociada a la división administrativa de Madrid. Esos mismos datos muestran asimismo cómo la viruela desapareció casi totalmente del panorama madrileño tras la pandemia de gripe de 1918-19, que coincidió — como he indicado - con una epidemia de viruela. A la hora de explicar esta circunstancia, no se debe descartar el papel que la gran crisis sanitaria representó de cara a crear actitudes favorables a la vacunación contra esta última enfermedad, tanto entre la población como entre las autoridades. En este sentido, es interesante recordar la importante labor propagandística desarrollada por

65 Revenga, R. (1901), p. 42; HAUSER, Ph. (1979), vol. 2, pp. 48-49. Este tema ha sido abordado recientemente en CAMPOS MARÍN, R. (2001), «La vacunación antivariólica en Madrid en el último tercio del siglo XIX. Entre el especialismo médico y el mecantilismo», Medicina e Historia, 4 (Cuarta época), pp. 1-15.

66 MARTÍN SALAZAR, M. (1913), pp. 137-138.

67 Esta situación contrasta con la escasa importancia que la mortalidad por viruela tuvo en el medio rural madrileño. Véase SANZ GIMENO, A. (1999), pp. 92-93.

68 Entre los testimonios contemporáneos sobre dichas epidemias y la —menos importante- de 1913, cabe citar los siguientes: MONMENEU LóPEZ REYNOSO, J. (1904), La epidemia de viruela en 19034, Madrid, Impr. de Nicolás Moya; y LASBEnNES, L. (1914), La viruela en Madrid en 1913, Madrid, Impr. Municipal. 
GRÁFICA 9. MORTALIDAD POR VIRUELA DE MADRID Y SUS DISTRITOS

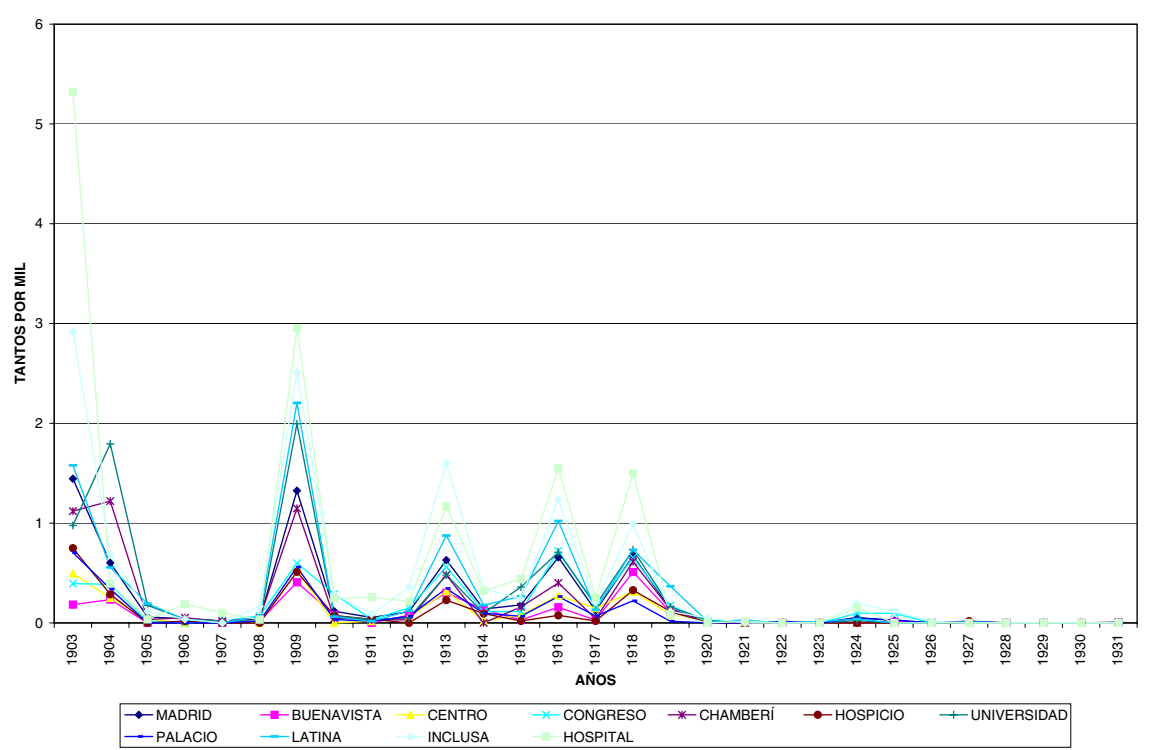

GRÁFICA 10. MORTALIDAD POR TUERCULOSIS PULMONAR, MADRID

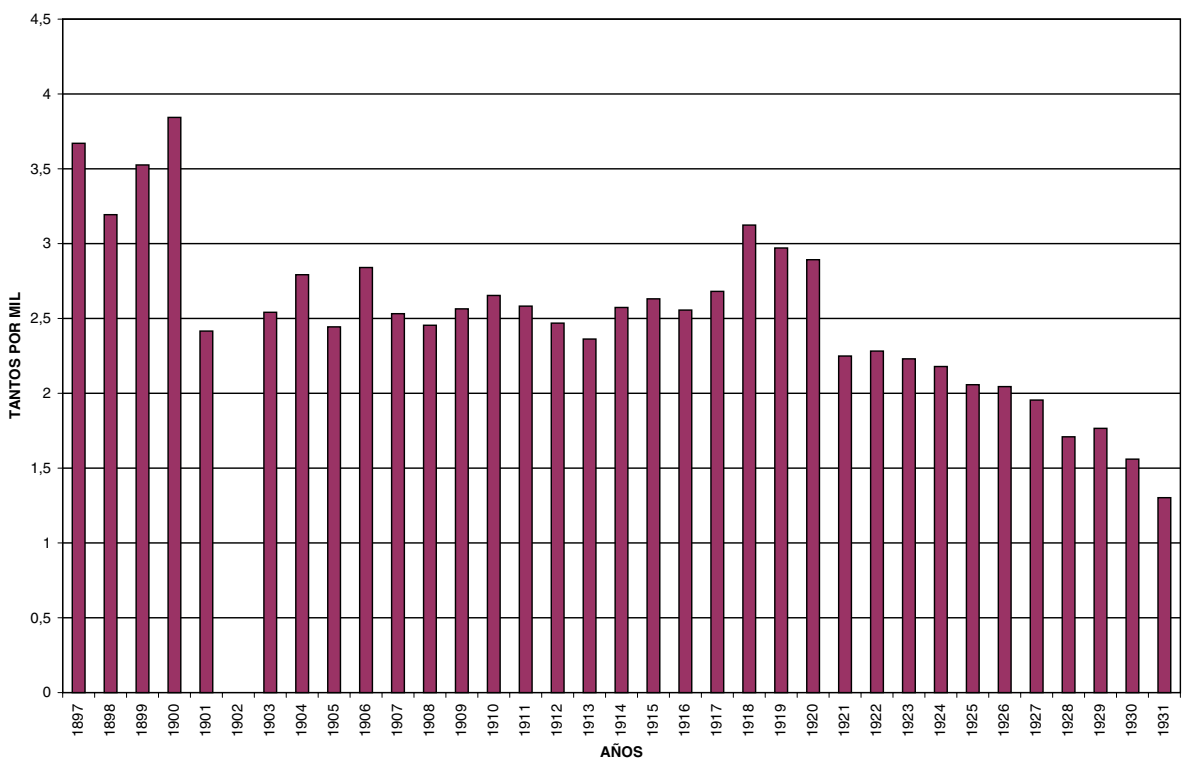


El Socialista, especialmente al término del segundo brote de la pandemia ${ }^{69}$. Otro de los efectos fue el Real Decreto del 10 de enero de 1919 relativo a la prevención de las enfermedades contagiosas, por el que se estableció la obligatoriedad de vacunarse contra la viruela «antes de los seis meses de edad», y de revacunarse «cada siete años hasta los treinta», siendo igualmente obligatorio que las personas de más edad que no hubieran cumplido estos requisitos se sometieran a dichas prácticas ${ }^{70}$. De modo que, por lo tanto, esa reducción y posterior desaparición de la viruela de todos los distritos madrileños se podría relacionar en buena medida con la correcta aplicación de las medidas contenidas en el citado decreto.

\section{COMPORTAMIENTO DE LA MORTALIDAD POR TUBERCULOSIS PULMONAR, POR GRI- PE Y OTROS PROCESOS RESPIRATORIOS}

La tuberculosis pulmonar era otra grave cuestión sanitaria que ensombrecía el panorama madrileño. Dicha enfermedad, según Hauser, había sido responsable de 22.106 defunciones desde 1889 hasta 1900. A pesar de ser importante esta cifra, que suponía entre un $10 \%$ y un $12 \%$ del total de fallecidos, era inferior a la de París y menor que las de la mayoría de las capitales del Mundo Occidental ${ }^{71}$. Por contra, las muertes por otros procesos respiratorios (bronquitis, pulmonía...) eran muy superiores a las de París. A la hora de interpretar estos datos, los autores apuntaban la posibilidad de que se hubiera producido un subregistro de las muertes por tuberculosis pulmonar a favor de las ocasionadas por las restantes enfermedades respiratorias ${ }^{72}$.

Como pone de relieve la gráfica 10 , se registraron altas tasas de mortalidad por tuberculosis pulmonar en los últimos años del siglo XIX, e incluso en 1900, alcanzándose en todos los casos valores superiores a 3\%, rebasándose con mucho las cifras correspondientes a España ${ }^{73}$. Con el cambio de siglo las tasas comenzaron a

69 El Socialista, 3421, 6 de diciembre de 1918, p. 3. Más información sobre el comportamiento de este diario obrero durante la pandemia de gripe de 1918-19, figura en: PORRAS GALLO, Ma I. (1992), pp. 125-144.

70 «Real Decreto del 10 de enero de 1919 en relación con la prevención de las enfermedades contagiosas», Medicina Social Española, 4, 69-75, p. 73.

71 HAUSER, Ph. (1979), vol. 2, pp. 126-130; LASBENNES, L. (1912), p. 37, cuadro 8; ÁlVAREZ RVillamil, V. (1912), Madrid y la tuberculosis, reproducido en MOLERO MESA, J. (1987), Estudios medicosociales sobre la tuberculosis en la España de la Restauración, Madrid, Ministerio de Sanidad y Consumo, 133-175, p. 157. Sobre el problema de la tuberculosis en Madrid en el período estudiado, pueden consultarse también CODINA CASTELlví, J. (1916), El problema social de la tuberculosis en Madrid. Discurso leído en la sesión inaugural del año de 1916 en la Real Academia de Medicina, Madrid, E. Teodoro, y otros testimonios contemporáneos incluidos en el volumen de MOLERO MESA, J. (1987).

72 HAUSER, Ph. (1979), vol. 2, pp. 128-130.

73 La mortalidad por tuberculosis pulmonar en España fue 200,0 por cien mil de 1860 a 1890 , y 200,6 por cien mil en 1900. LóPEZ PiÑERO, J. Ma (1990), Historia de la Medicina, Madrid, Historia 16, 
disminuir, aunque continuaron siendo superiores a las del conjunto de nuestro país ${ }^{74}$. Como muestra la gráfica 10 , los descensos se alternaron con algunas elevaciones que culminaron con las altas cifras registradas en 1918, 1919 y 1920, como consecuencia del efecto negativo que la pandemia de gripe de 1918-19 y su epidemia satélite de 1919-1920 tuvieron en los enfermos tuberculosos ${ }^{75}$. A estas elevaciones sucedió una disminución mantenida de la mortalidad por tuberculosis pulmonar, registrándose en $1930(1,56 \%)$ y $1931(1,30 \%)$ unas tasas inferiores a la de 1900 en más de un $50 \%$ y en torno a un punto menos que la de $1901(2,42 \%)^{76}$. A pesar de lo que esto pueda significar de cara a valorar la efectividad de la lucha antituberculosa emprendida en Madrid ${ }^{77}$ y de las mejoras producidas en las condiciones higiénico-sanitarias y sociales de dicha ciudad, es preciso indicar, no obstante, que en 1930 las muertes por tuberculosis representaban todavía algo más del $9 \%$ del total de las muertes anuales, y en 1931 el 7,65\%.

La tendencia general descendente de la mortalidad por tuberculosis pulmonar desde los primeros años del siglo XX se observa en todos los distritos madrileños (Gráfica 11), advirtiéndose igualmente la elevación registrada coincidiendo con la pandemia de gripe de 1918-19 y su posterior descenso ${ }^{78}$. A pesar de ello, el distrito de Hospital continuó manteniendo altas tasas al final del período estudiado, siendo $3 \%$ el valor correspondiente a 1931. Nuevamente, se aprecia la existencia de una mortalidad diferencial por distritos. Así, las menores cifras se registraron en Buenavista, Centro, Palacio, Hospicio y Congreso (que tuvo, no obstante, unos picos en

p. 147. Una relación de los valores registrados entre 1901 y 1930 figura en: PASCUA, M. (1934), Mortalidad en España por rúbricas de la lista internacional abreviada de causas de defunción, y algunos otros indices de movimiento de población, Madrid, Dirección General de Sanidad.

74 Martín SAlazar, M. (1913), p. 115; ÁlVAREZ R-VilLAMIL, V. (1912), p. 141.

75 Porras Gallo, $M^{\mathrm{a}}$ I. (1996b), pp. 220-232; PORRAS GAllo, $\mathrm{M}^{\mathrm{a}}$ I. (1996c), p. 83; PORRAS GALLO, Ma I. (1997), p. 63.

76 Estas cifras son también superiores a las registradas en la mayoría de los países del mundo occidental, aunque en todos ellos la mortalidad por tuberculosis pulmonar siguió un patrón muy similar durante el primer tercio del siglo XX. MERCER, A. (1990), Disease, Mortality and Population in Transition, Leicester, London and New York, Leicester University Press, p. 105; PURANEN, B. (1991), «Tuberculosis and the Decline of Mortality in Sweden», en SCHOFIELD, R.; REHER, D. \& BIDEAU, A. (eds.), The Decline of Mortality in Europe, Oxford, Clarendon Press, 97-117, p. 103.

77 Sobre este tema, pueden consultarse: MOLERO MESA, J. (2001), «"iDinero para la cruz de la vida!" Tuberculosis, beneficencia y clase obrera en el Madrid de la Restauración», Historia Social, 39, pp. 31-48; Molero Mesa, J. (1987), Estudios medicosociales sobre la tuberculosis en la España de la Restauración, Madrid, Ministerio de Sanidad y Consumo, pp. 21-36; MOLERo MESA, J. (1989), Historia social de la tuberculosis en España (1889-1936), Universidad de Granada, Tesis doctoral; RODRÍGUEZ OCAÑA, E. (1992), pp. 133-148; y BÁGUENA CERVELLERA, Mª. (1992), La tuberculosis y su historia, Barcelona, Fundación Uriach.

78 A modo de orientación, es interesante señalar que las tasas de los distritos madrileños en 1903 eran generalmente superiores a las de los distritos de Londres de 1900, que figuran en: HARDY, A. (1993), pp. 216-217. 
GRÁFICA 11. MORTALIDAD POR TUBERCULOSIS PULMONAR DE MADRID Y SUS DISTRITOS

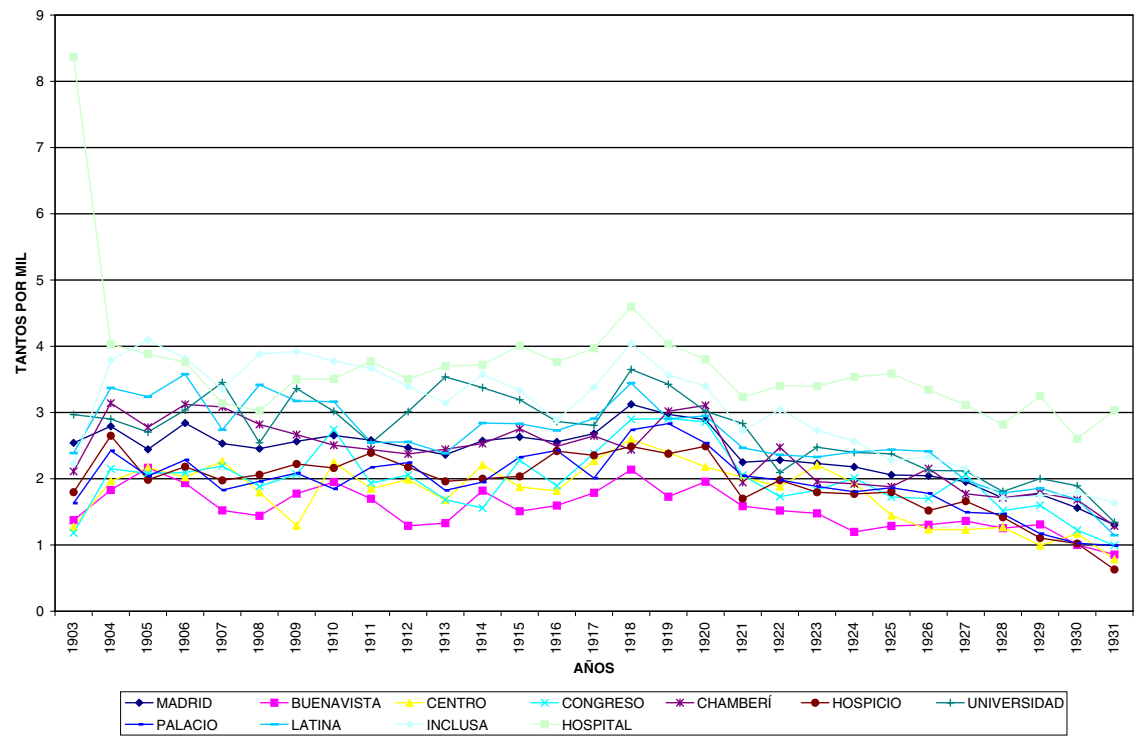

GRÁFICA 12. MORTALIDAD POR RESTOS DE ENFERMEDADES RESPIRATORIAS, MADRID

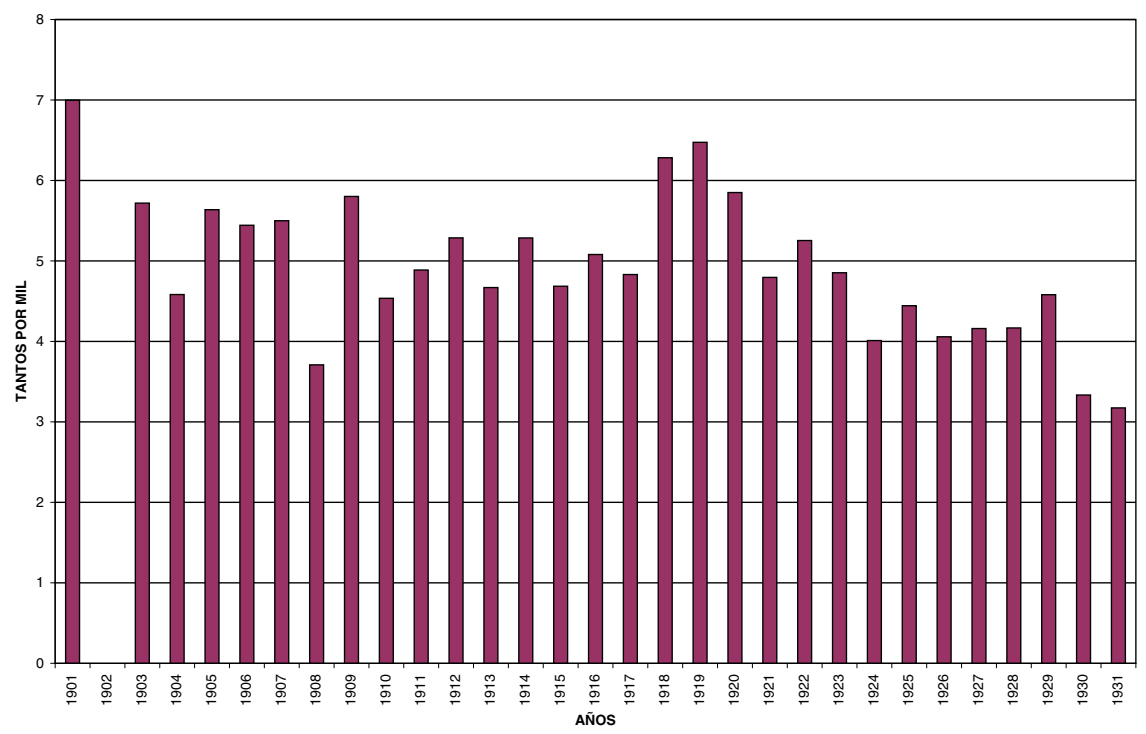


1924 y 1927), los distritos más favorecidos; mientras que las cotas más altas se alcanzaron en Hospital, Inclusa y Universidad. A su vez, Latina y Chamberí tuvieron unos valores medios muy próximos a los obtenidos para el conjunto de Madrid. No obstante, como muestra la gráfica 11, las diferencias fueron reduciéndose con el paso de los años. De hecho, en 1931, aunque se mantenía la estratificación tripartita, se habían operado algunos cambios, ya que en esa fecha tan sólo Hospital poseía las tasas más altas, habiendo pasado Inclusa y Universidad al nivel intermedio, y habiéndose acercado cuantitativamente al grupo más favorable.

A pesar de la importancia que, como he indicado, poseía la mortalidad por tuberculosis pulmonar, ésta no era la única enfermedad respiratoria que se presentaba como un problema sanitario para Madrid. De hecho, según Hauser, los procesos respiratorios fueron responsables de mayor número de muertes que la tuberculosis en los últimos años del siglo XIX ${ }^{79}$. En efecto, como pone de relieve la gráfica 12, las tasas de mortalidad por las otras patologías respiratorias fueron casi el doble que las correspondientes a la tuberculosis pulmonar (Gráfica 10) a lo largo del período estudiado. No obstante, en 1903, se inició un descenso de dichas tasas que se alternó con algunas elevaciones, como las producidas con motivo de la pandemia de gripe de 1918-19 y su satélite de 1919-20. Superado el efecto de estos episodios epidémicos, el descenso se hizo más mantenido, especialmente desde 1924 (pese a los picos de 1925 y 1929), alcanzándose en 1930 (3,33\%) y 1931 (3,17\%) valores inferiores casi en un $50 \%$ a los de 1901. Sin embargo, a pesar de la reducción registrada, en 1931, las muertes por enfermedades respiratorias seguían constituyendo casi el $20 \%$ del total de fallecidos ${ }^{80}$.

El patrón comentado se siguió en todos los distritos madrileños, salvo Congreso. En este caso, las cifras bajas que caracterizaron los primeros años del siglo XX, dieron paso a una elevación progresiva que se mantuvo al término de la pandemia de gripe de 1918-19. De modo que, como se puede ver en la gráfica 13, desde 1922 los valores coincidían con los de Madrid en su conjunto o los superaban, para alcanzar las cotas más altas a finales de los años veinte, teniendo en 1931 la tasa más alta $(4,14 \%)^{81}$. De forma que Congreso compartió las menores cifras con Buenavista, Hospicio, Centro y Palacio en las primeras décadas, mientras que desde 1922 detentó las mayores con Hospital, Inclusa y Latina. Comportamiento inverso fue el de Universidad, que mantuvo una de las cifras más elevadas hasta 1919, pero desde esa fecha alcanzó unos valores medios, similares a los de Chamberí y Madrid en su con-

79 HAUSER, Ph. (1979), vol. 2, p. 128.

80 Un patrón similar se siguió en el conjunto de nuestro país. Para más información sobre esta cuestión, consúltese: PASCUA, M. (1935), Mortalidad específica en España II, Madrid, Publicaciones oficiales de la C.P.I.S., st. Tablas 50-56.

81 Posiblemente, este comportamiento estuvo relacionado con la inauguración de la Maternidad de Santa Cristina y el traslado de la Inclusa a O'Donnell en 1925. 
junto. En suma, en esta ocasión se advierte también una mortalidad diferencial que, como se ha visto, sufrió alguna modificación con el paso de los años y, como muestra la gráfica 13 , se redujo al término del período estudiado.

Otra entidad respiratoria protagonista del período analizado fue la gripe. Como permite ver la gráfica 14, esta entidad morbosa parece haber sido sólo un problema importante para la ciudad de Madrid con motivo de las grandes pandemias ${ }^{82}$. A las de 1918-19 y 1919-20, habría que añadir también la de 1889-90, que, aunque no figuran sus tasas en la gráfica 14, tuvo una importante repercusión en la mortalidad general de Madrid (Gráfica 1) ${ }^{83}$. La gráfica 15 muestra cómo la mortalidad diferencial de los distritos madrileños frente a esta enfermedad es menor que para los otros procesos analizados en este trabajo, y cómo esas diferencias se redujeron aún más con posterioridad a la gran pandemia del siglo XX. Esta misma gráfica (15) pone de relieve igualmente cómo, mientras que Hospital, Inclusa, Congreso y Chamberí registraron una mayor mortalidad en 1918, Buenavista, Centro, Hospicio, Universidad y Palacio lo hicieron en $1919^{84}$.

\section{EVOLUCIÓN DE LA MORTALIDAD POR DIFTERIA}

Como muestra la gráfica 16, la mortalidad por difteria en Madrid, que tuvo comparativamente menos importancia en el período estudiado ${ }^{85}$, presentó también una tendencia al descenso a lo largo del presente siglo, que se vio interrumpida sólo con motivo de las epidemias de 1907 y, sobre todo, de las de 1912-13-14. Una disminución más mantenida se registró a partir de 1920 , siendo las tasas de $1930(0,03 \%)$ y 1931 (0,03\%) cinco veces inferiores a la de $1903(0.15 \%)$.

En cuanto a la distribución de las tasas por distritos, cabe señalar que, como pone de manifiesto la gráfica 17, en los primeros años del siglo la mortalidad diferencial frente a la difteria era más llamativa y siguió un patrón similar al observado para la mayoría de los procesos analizados en este trabajo. Con posterioridad, especialmente

82 En este sentido, es preciso recordar que, dadas las características clínicas de la gripe, suele existir un subregistro importante de la mortalidad por esta enfermedad, inclusive durante las epidemias.

83 Según Hauser, la pandemia de gripe de 1889-90 provocó 2.881 defunciones. HAUSER, Ph. (1979), vol. 2, pp. 100-101.

84 Mayor información sobre las repercusiones demográficas de la pandemia de gripe de 1918-19 y de su satélite de 1919-20 en los distritos de Madrid, figura en: PORRAS GALlO, M ${ }^{\text {a }}$ I. (1996b), pp. 201239; PorRAs GAllo, Ma I. (1996c), pp. 79-83; y PORRAS GALlO, Mª I. (1997), pp. 56-61.

85 En este sentido, es interesante señalar que la mortalidad por difteria de Madrid parece que, conforme a los datos facilitados por A. Hardy, fue ligeramente inferior a la de Londres entre 1897 y 1900. HARDY, A. (1993), p. 105. Una pequeña idea acerca de la situación de esta enfermedad al inicio del siglo XX, figura en La difteria en Madrid. Proyecto de hospitalito para el tratamiento de niños diftéricos, Madrid, E. Teodoro, 1901. 
GRÁFICA 13. MORTALIDAD POR RESTO DE ENFERMEDADES RESPIRATORIAS

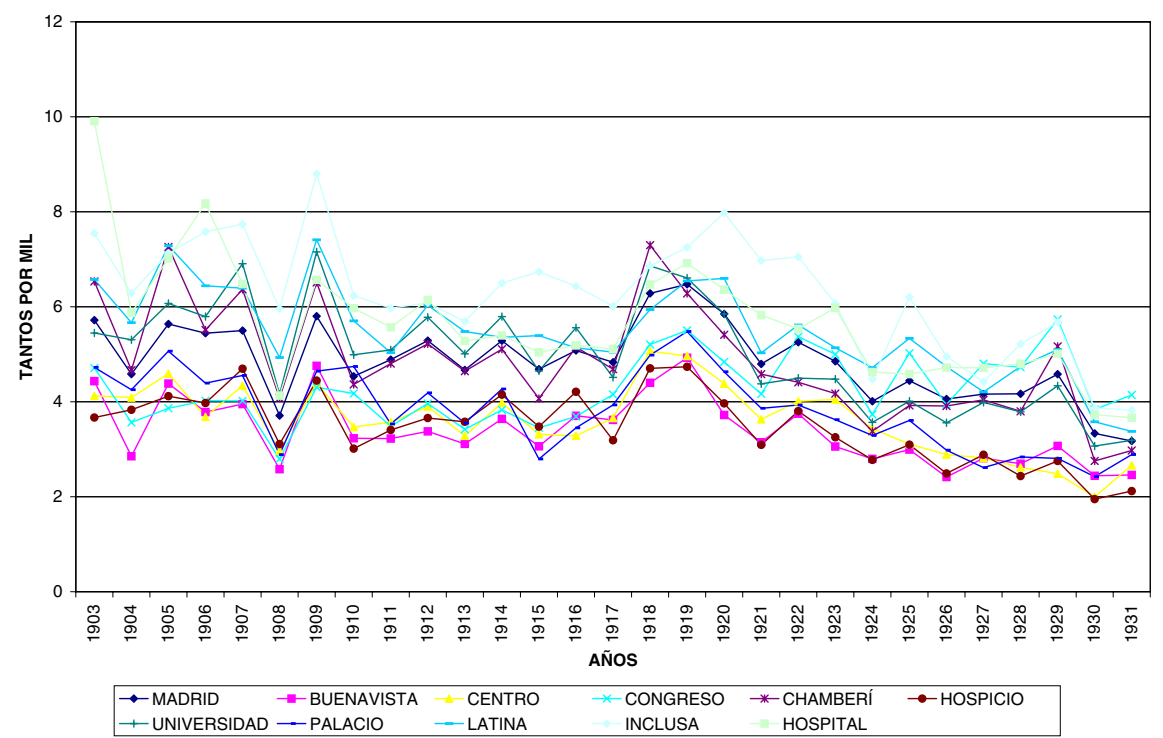

GRÁFICA 14. MORTALIDAD POR GRIPE, MADIRD

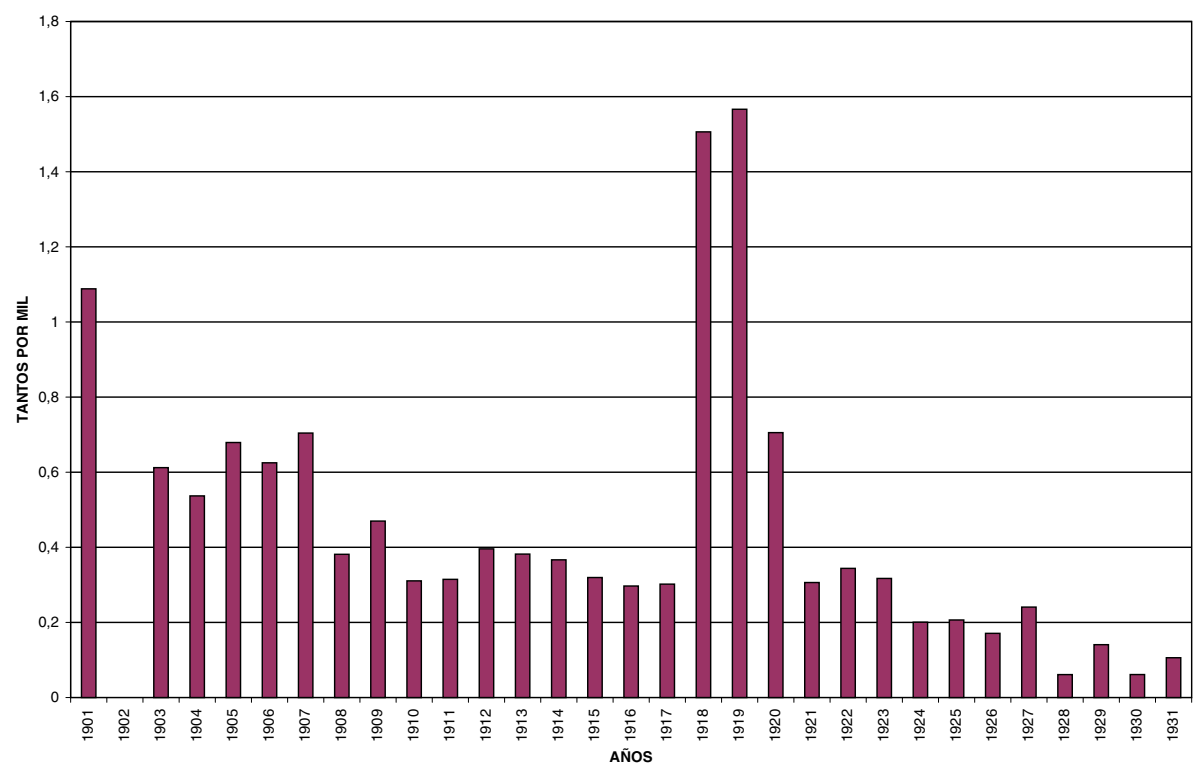


GRÁFICA 15. MORTALIDAD POR GRIPE DE MADRID Y SUS DISTRITOS

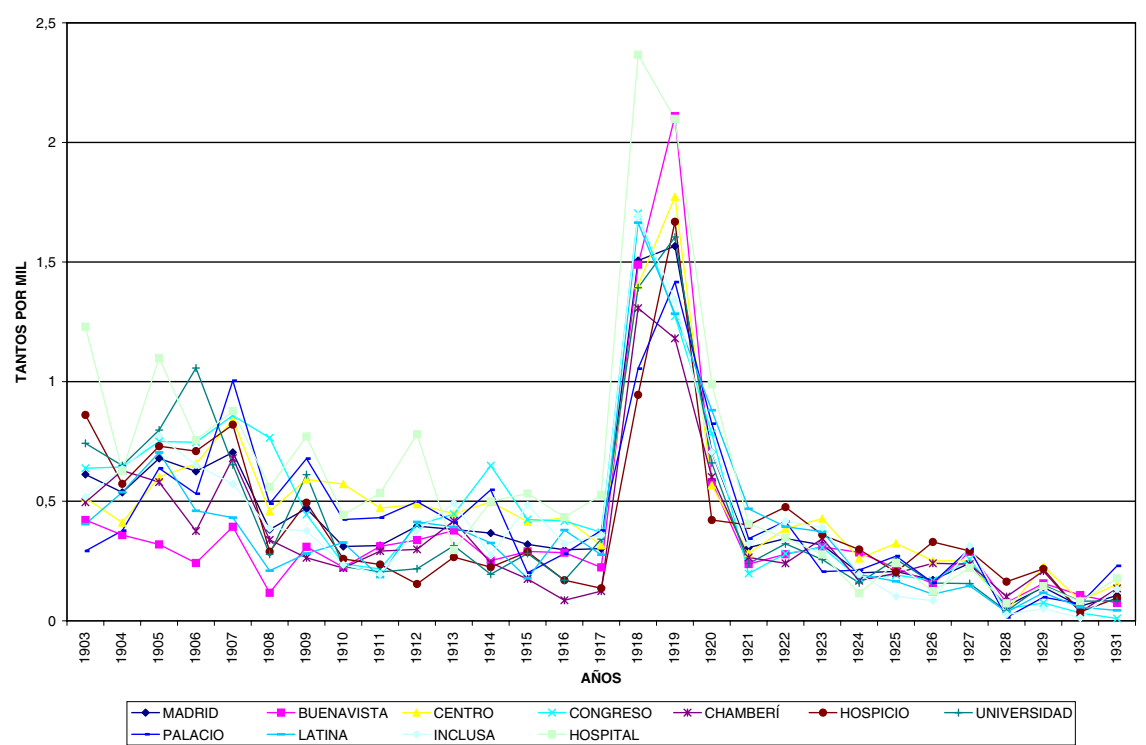

GRÁFICA 16. MORTALIDAD POR DIFTERIA, MADRID

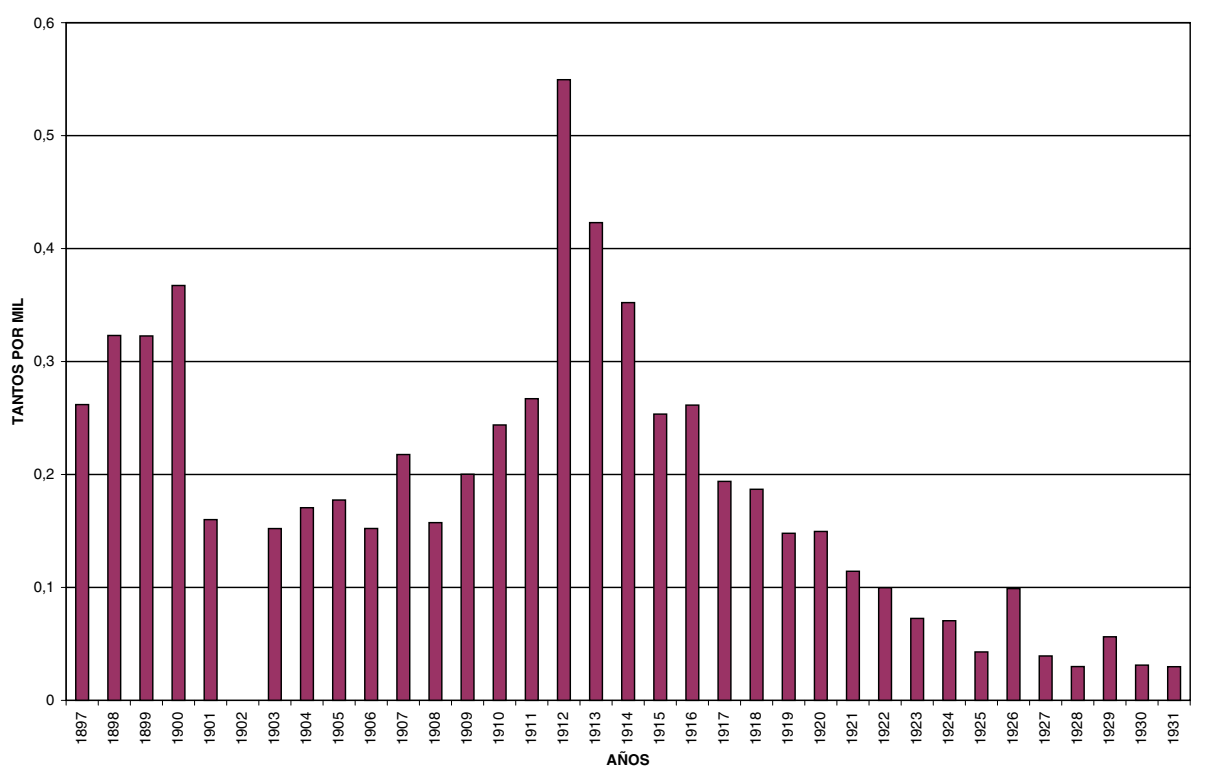


a partir de 1920, dicha mortalidad diferencial se redujo progresivamente hasta ser casi inapreciable en 1931. De hecho, en esa fecha, casi todos los distritos presentaban valores comprendidos entre $0,01-0,02 \%$, salvo Inclusa $(0,07 \%)$ y Chamberí $(0,1 \%)$, que poseían las tasas más elevadas.

A la hora de explicar la notable disminución de muertes por difteria registrada en Madrid en el período analizado, es preciso valorar el efecto que pudieron tener los cambios producidos en el tratamiento de dicha enfermedad, especialmente la extensión de la seroterapia ${ }^{86}$. De hecho, la puesta a punto del suero antidiftérico en 1894 introdujo importantes mejoras en el rendimiento de las dos técnicas operatorias empleadas hasta entonces, y mejoró el pronóstico de los afectados por la difteria. La aplicación del suero simultáneamente con la intubación convirtió a esta última en la práctica quirúrgica de elección, quedando reservada la traqueotomía para situaciones de absoluta necesidad ${ }^{87}$. Precisamente, esta terapia combinada fue el tratamiento seguido en el Instituto Llorente de Madrid desde su creación en 1895. Esta institución de carácter privado fue la primera de estas características que se fundó en la capital para la producción y aplicación del suero antidiftérico. Con posterioridad, en enero de 1899, el suero antidiftérico comenzó a utilizarse también en la Beneficencia municipal, concretamente en la Consulta de Enfermedades de la nariz, garganta y oídos de la Casa de Socorro del distrito de Palacio ${ }^{88}$. A través de los centros mencionados y de otros surgidos posteriormente - como el Servicio Antidiftérico municipal, existente en la Casa de Socorro de Centro en $1916^{89}$ _, parece que alcanzó gran difusión la nueva terapia ${ }^{90}$. Más tarde, en 1912, se contaría igualmente con una vacuna, de uso muy limitado hasta que fue reemplazada por la preparada por Gaston Léon Ramón en 1923 en el Instituto Pasteur. Esta nueva vacuna se difundiría por los servi-

86 Mayor información sobre este tema, puede obtenerse en RODRÍGUEZ OCAÑA, E. (1994) y (1996).

87 La disminución de la inflamación y el reblandecimiento de las falsas membranas subsiguiente a la administración del suero antidiftérico impedía la oclusión del conducto y facilitaba la retirada temprana del tubo, evitándose las secuelas debidas a una intubación prolongada. RODRÍGUEZ OCAÑA, E. (1996), p. 162.

88 Esta medida, tomada por el Ayuntamiento de Madrid, constituyó el primer paso de lo que sería posteriormente el Instituto Municipal de Seroterapia y Laringología. RodRíGuEZ OCAÑA, E. (1996), pp. 162-163.

89 Aunque el Ayuntamiento madrileño había aprobado en 1912 un proyecto de creación de un Servicio Antidiftérico municipal, el permiso para su instalación no se obtuvo hasta 1914, existiendo constancia de su funcionamiento en 1916. En 1928, pasó a denominarse Instituto de [Laringología y] Sueroterapia, continuando su actividad durante la Segunda República. Información extraída de varios expedientes del Archivo Histórico de la Villa de Madrid (18-159-92; 21-225-122; 19-434-89; 27-81-1; 29-387-22; 29387-18; 29-386-10 y 29-386-8), que me ha sido facilitada por E. Rodríguez Ocaña.

90 De hecho, el Instituto Llorente afirmaba haber tratado más de 16.800 enfermos entre 1894 y 1914. Llorente, V. (1914), Difteria y su curación. Bases en que descansa la acertada aplicación de la Seroterapia, Madrid, Suc. Rivadeneyra. 
cios provinciales de Higiene hacia $1933^{91}$. De modo que, a tenor de lo expuesto hasta ahora, parece apropiado atribuir a la seroterapia antidiftérica un papel notable en el descenso de muertes por difteria en Madrid durante el período estudiado, pero es preciso tener también en cuenta que no fue el único factor responsable de dicho descenso. De hecho, una tendencia descendente en la mortalidad por dicha enfermedad se detecta en toda Europa desde $1886^{92}$.

\section{GRÁFICA 17. MORTALIDAD POR DIFTERIA DE MADRID Y SUS DISTRITOS}

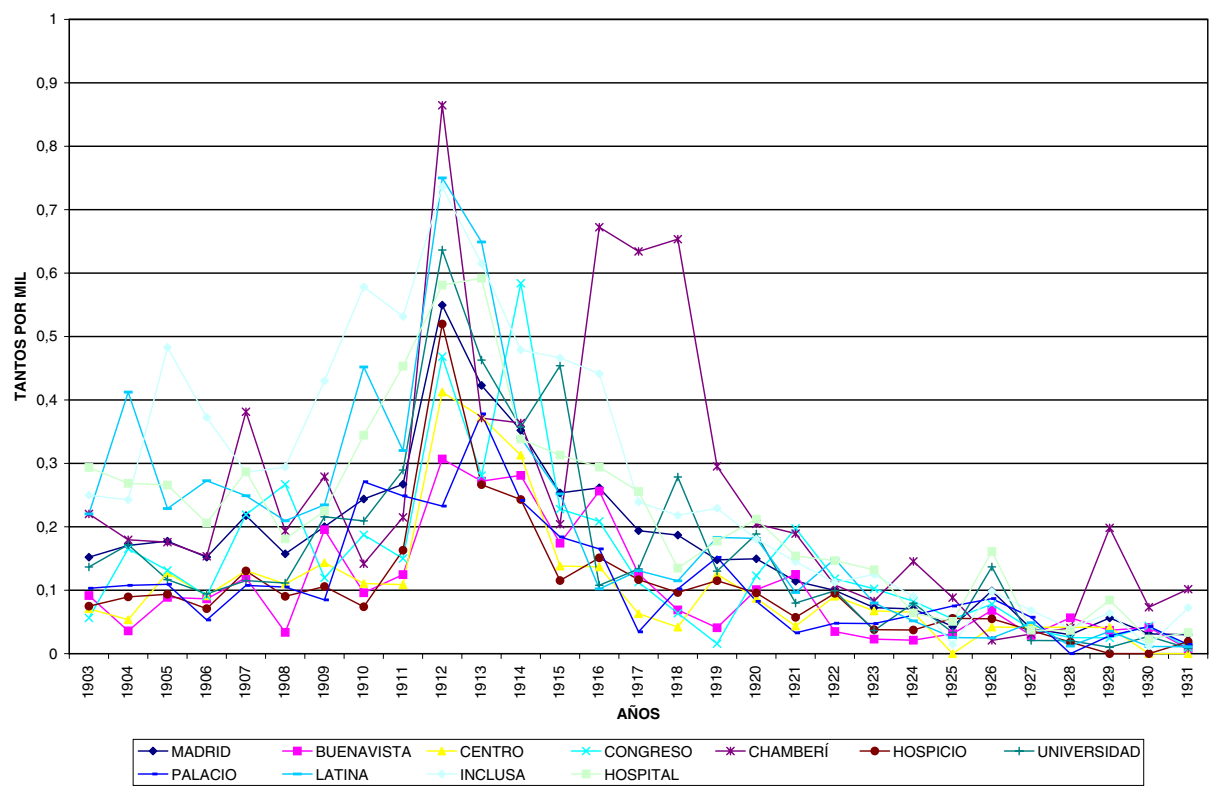

\section{COMENTARIO FINAL}

A modo de resumen de lo presentado en este trabajo, cabe decir que las elevadas tasas de mortalidad general e infantil y de la mayor parte de las enfermedades infecciosas registrada en Madrid y la mayoría de sus distritos en el tránsito del siglo XIX

91 Nueva contribución al estudio de la vacunación antidiftérica. Academia Nacional de Medicina. Sesión del 28 de octubre, El Siglo Médico, 92 (1933), pp. 507-508; cit. en RodríGuEZ OCAÑA, E. (1996), p. 164.

92 RoDrígueZ OCAÑA, E. (1996), p. 163. Sobre la presencia de la difteria en Londres y la lucha llevada a cabo en los últimos años del siglo XIX, véase el interesante trabajo de: HARDY, A. (1993), pp. 80-109. 
al XX, corroboran los testimonios relativos a su mala situación higiénico-sanitaria. A su vez, la variabilidad de las cifras alcanzadas por los diferentes distritos pone de relieve la desigualdad frente a la enfermedad asociada a la división administrativa de la capital, y que estaba ligada a su estratificación horizontal higiénico-urbanística y socio-económica. No obstante, la reducción de los valores de las distintas tasas de mortalidad analizadas que se experimentó, - primero lentamente y desde mediados de la tercera década, de forma más mantenida-, muestran cómo se estaba efectuando en el período analizado la transición sanitaria. Conforme a lo expuesto, parece apropiado considerar dicha transición como el resultado de la acción conjunta de las pequeñas mejoras introducidas en distintos ámbitos, siendo por tanto necesario valorar el papel tanto de los cambios operados en el saneamiento urbano, condiciones de las viviendas, abastecimiento y control de calidad de los alimentos, como de la mayor disponibilidad de recursos médico-asistenciales (vacunaciones, sueros, mejora de la red asistencial...), del auge de la divulgación higiénico-sanitaria, así como de las modificaciones efectuadas en materia de protección a la infancia, en el mundo del trabajo y en el de la educación.

Agradezco a Mercedes del Cura la recogida de los datos demográfico-sanitarios que he utilizado para la elaboración del presente trabajo. 